NATIONAL AERONAUTICS AND SPACE ADMINISTRATION

(NASA-CR-145919) THE EFFECTS OF, AN

ION-THRUSTER EXHAUST PLUME ON S-BAND CARRIER

N76-14345

TRANSUISSION (Jet Propulsion:Lab.), $67 \mathrm{p}$ HC

$\$ 4.50=$

CSCI $20 \mathrm{~N}$

Unclas

G3/32 06804

Technical Memorandum 33-754

The Effects of an Ion-Thruster Exhaust

Plume on S-Band Carrier Transmission

William E. Ackerknecht III

Philip H. Stanton

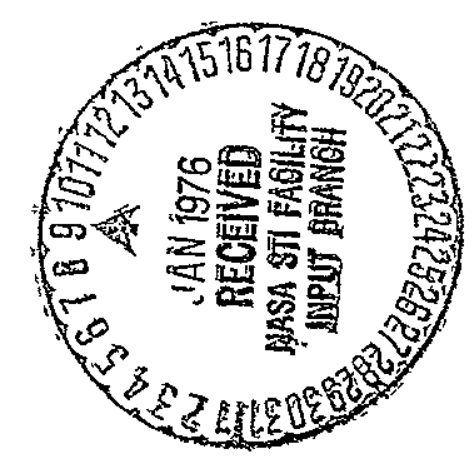

JET PROPULSION LABORATORY

CALIFORNIA INSTITUTE OF TECHNOLOGY

PASADENA, CALIFORNIA

January 1,1976 
NATIONAL AERONAUTICS AND SPACE ADMINISTRATION

Technical Memorandum 33-754

\title{
The Effects of an Ion-Thruster Exhaust Plume on S-Band Carrier Transmission
}

\author{
William E. Ackerknecht III \\ Philip H. Stanton
}

JET PROPULSION LABORATORY CALIFORNIA INSTITUTE OF TECHNOLOGY

PASADENA, CALIFORNIA

January 1, 1976 
Prepared Under Contract No NAS 7-100 National Aeronautics and Space Administration 
TECHNICAL REPORT STANDARD TITLE PAGE

\begin{tabular}{|c|c|c|c|c|c|}
\hline 1. Report No. 33-754 & \multicolumn{2}{|c|}{ 2. Government Accession No. } & \multicolumn{3}{|c|}{ 3. Recipient's Catalog No. } \\
\hline \multirow{2}{*}{\multicolumn{3}{|c|}{$\begin{array}{l}\text { 4. Title and Subtitle } \\
\text { THE EHFECTS OF AN ION-THRUSTER EXXHAUST } \\
\text { PLUME ON S-BAND CARRIER TRANSMTSSION }\end{array}$}} & \multicolumn{3}{|c|}{ 5. Report Date January 1, 1976} \\
\hline & & & \multicolumn{3}{|c|}{ 6. Performing Organization Code } \\
\hline \multicolumn{3}{|c|}{$\begin{array}{l}\text { 7. Author(s) William E. Ackerknecht III } \\
\text { Philip H. Stanton }\end{array}$} & \multicolumn{3}{|c|}{ 8. Performing Organization Report No. } \\
\hline \multirow{3}{*}{\multicolumn{3}{|c|}{$\begin{array}{l}\text { 9. Performing Organization Name and Address } \\
\text { JET PROPULSION LABORATORY } \\
\text { California Institute of Technology } \\
\text { 4800 Oak Grove Drive } \\
\text { Pasadena, Callfornia } 91103\end{array}$}} & \multicolumn{3}{|c|}{ 10. Work Unit No. } \\
\hline & & & \multicolumn{3}{|c|}{$\begin{array}{c}\text { 11. Contract or Grant No. } \\
\text { NAS } 7-100\end{array}$} \\
\hline & & & \multirow{2}{*}{\multicolumn{3}{|c|}{$\begin{array}{l}\text { 13. Type of Report and Period Covered } \\
\text { Technical Memorandum }\end{array}$}} \\
\hline \multirow{2}{*}{\multicolumn{3}{|c|}{$\begin{array}{l}\text { 12. Sponsoring Agency Name and Address } \\
\text { NATIONAL AERONAUTICS AND SPACE ADMINISTRATION } \\
\text { Washington, D.C. } 20546\end{array}$}} & & & \\
\hline & & & \multicolumn{3}{|c|}{ 14. Sponsoring Agency Code } \\
\hline \multicolumn{6}{|l|}{ 15. Supplementary Notes } \\
\hline \multicolumn{6}{|c|}{$\begin{array}{l}\text { 16. Abstract } \\
\text { The development of electric propulsion for spacecraft applications introduces } \\
\text { a plasma medium which may affect the spacecraft-Earth } \mathrm{S-band} \text { communication } \\
\text { system. The objectives of the study reported here are (1) to measure the } \\
\text { order of magnitude of the effects of an ion-thruster plume on s-band signals, } \\
\text { and (2) to develop modeling techniques to predict the effects. } \\
\text { The measured results show that the } \mathrm{RF} \text { signal transmitted through an ion- } \\
\text { thruster plume is reduced in amplitude and shifted in phase. Both the signal } \\
\text { amplitude and signal phase experience a significant increase in noise when } \\
\text { passing through the plume. For beam currents between } 1.0 \text { A and } 1 \text {. } 7 \text { A, the } \\
\text { measured loss was between about }-0.3 \text { dB and -l.3 dB and the measured phase } \\
\text { shift was between about } 20^{\circ} \text { and } 45^{\circ} \text {. Many of the experimental problems } \\
\text { encountered were not correctable during the short measurement period, so } \\
\text { part of this report presents suggestions for the follov-up measurement } \\
\text { program. }\end{array}$} \\
\hline \multicolumn{2}{|c|}{$\begin{array}{l}\text { 17. Key Words (Selected by Author(s)) } \\
\text { Spacecraft Communications, Command } \\
\text { and Tracking } \\
\text { Spacecraft Propulsion and Power } \\
\text { Communications } \\
\text { Space Sciences (General) }\end{array}$} & \multicolumn{4}{|c|}{$\begin{array}{l}\text { 18. Distribution Statement } \\
\text { Unclassified -- Unlimited }\end{array}$} \\
\hline $\begin{array}{l}\text { 19. Security Classif. (of this report) } \\
\text { Unclassified }\end{array}$ & $\begin{array}{r}\text { 20. Security } \\
\text { Unc }\end{array}$ & $\begin{array}{l}\text { lassif. (of this } \\
\text { assified }\end{array}$ & & $\begin{array}{l}\text { 21. No. of Pages } \\
59\end{array}$ & 22. Price \\
\hline
\end{tabular}




\section{HOW TO FILL OUT THE TECHNICAL REPORT STANDARD TITLLE PAGE}

Make items 1, 4, 5, 9, 12, and 13 agree with the corresponding information on the report cover. Use all capital letters for title (item 4). 'Lèave items 2, "6, and ${ }^{-14}$, blank. Complete the remaining items as follows:

3. Recipient's Catalog No. Reserved for use by report recipients.

7. Author(s). Include corresponding information from the report cover. In addition, list the affiliation of an author if it differs from that of the performing organization.

8. Performing Organization Report No. Insert if performıng organization wishes fo-assign this number.

10. Work Unit No. Use the agency-wide code (for example, 923-50-10-06-72), which uniquely identıfies the work unit under which the work was authorized. Non-NASA performing organizations will leave this blank.

11. Insert the number of the contract or grant under which the report was prepared.

15. Supplementary Notes. Enter information not included elsewhere but useful, such as: Prepared in cooperation with... Translation of (or by)... Presented at conference of... To be published in...

- 16. Abstract. Inctude a brief (not to exceed 200 words) fáctual summary of the " most significant-information contained in the report. If possible, the

$\therefore$ abstract of a classified report should be unclassified. If the report contains. - a significant bibliography or literature survey, 'mention it here. '

17. Key Words. Insert terms or short phrases selected by the author that identify the principal subjects covered in the greport, and that are sufficiently

i specific and precsse to be used for cafaloging.

18. Distribution Statement. Enter one of the áuthorized statements used to

.. denote releasability to the public or a limitation on dissemination for "

' reasons-other than security of defense information. Authorized statements

- are "Unclassified-Unlimited, "U. S. Government and Contractors 'only," ..

$\because$ "U.S. Government Agencies only," and "NASA and'-NASA Confractors only."

19. Security Classification (of report). NOTE: Reports carrying a security classification will require additional markings giving security and downgrading information as specified by the Security Requirements Checklist and the DoD Industrial Security Manual (DoD 5220.22-M).

20. Security Classification (of this page). NOTE: Because this page may be used in preparing announcements, bibliographies, and data banks, it should be unclassified if possible. If a classification is required, indicate separately the classification of the title and the abstract by following these ttems with either "(U)" for unclassified, or "(C)" or "(S)" as applicable for classified items.

'21.' No. of Pages. Insert the number of pages.

22. Price. Insert the price set by the Clearinghouse for Federal Scientific and Technical Information or the Government Printing Office, if kno'wn. 
PREFACE

The work described in this report was performed by the Telecommunications Division of the Jet Propulsion Laboratory. 


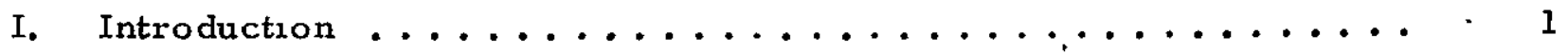

II. Analytical Models ........................... 2

A. Assumptions ........................ 2

1. Electron Plasma ................... 2

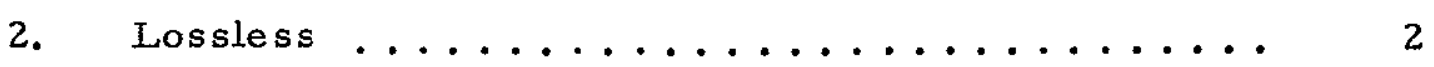

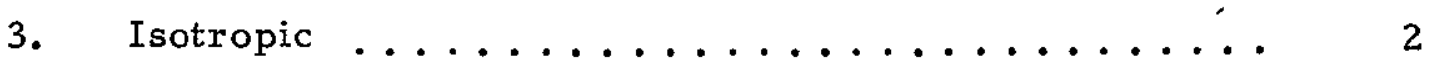

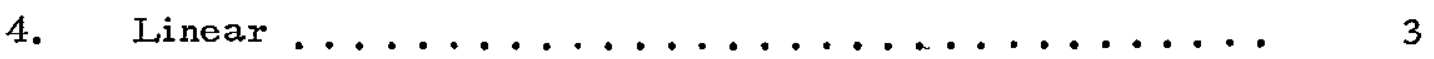

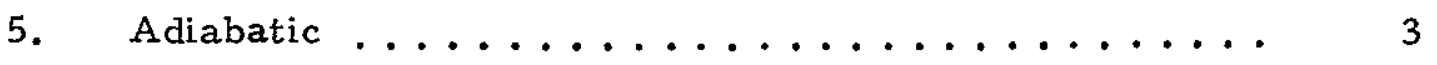

6. Permeability ...................... 3

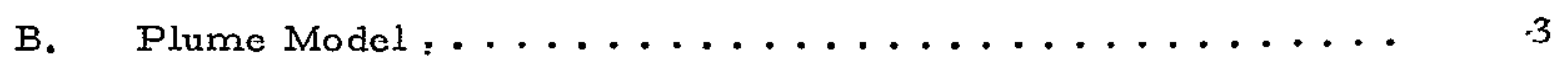

C. Interaction Model ..................... 4

1. Phase Shift ...................... 4

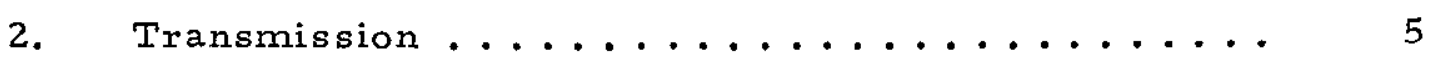

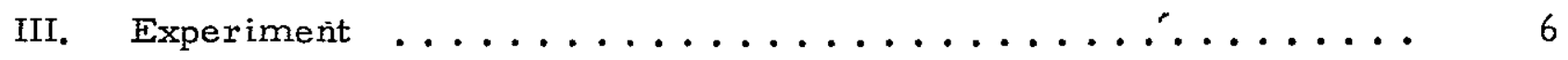

A. Experimental Approach .................. 6

B. Test Environment...................... 6

C. Equipment ...................... 7

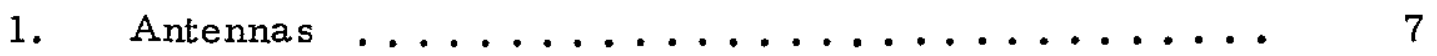

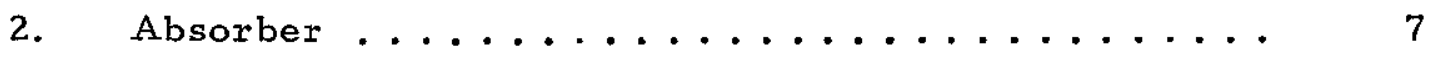

3. Instrumentation ................... 8

4. Thruster......................... 8

D. Test Procedures ........................... 9

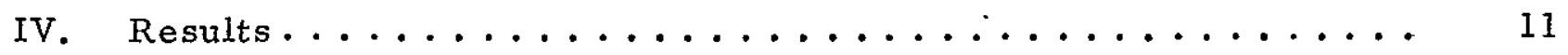

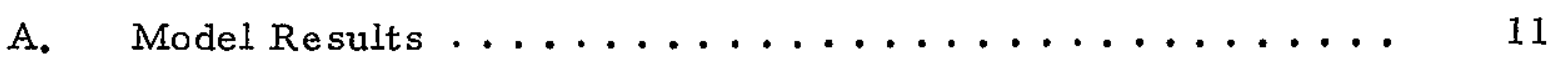

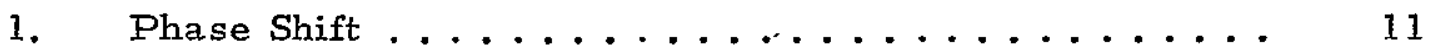


2. Transmission .................. 11

B. Experimental Results .................. 11

1. Analog Data Analysis ............... 12 .

2. Sampled Data Analysis ................. 14

a.. Time Averages. . . ............. 14

b. Distrubutions................. 15

c. Spectral Analysis ............... 16

3. Measurement Summary $\ldots \ldots \ldots \ldots \ldots \ldots$. 17

C. Comparisons.................... 17

v. Conclusions ............................ 19

\section{APPENDIXES}

A. Calculations ...................... 39

B. Horn Antennas ..................... 51

C. Microwave Absorber Tests ................ 53

D. Equipment List ..................... 55

E. Thruster Parameters $\ldots \ldots \ldots \ldots \ldots \ldots \ldots \ldots$

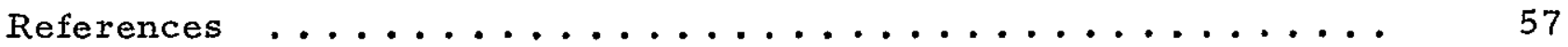

Definition of Symbols ..................... 58

\section{TABLES}

1. Two-minute average, signal amplitude and phase changes at various thruster operating current levels .........

B-1. Antenna test data .................

1. Geometry of the plume model .............. 22

2. Typical propagation path electron density profıle at $1.0 \mathrm{~A}$

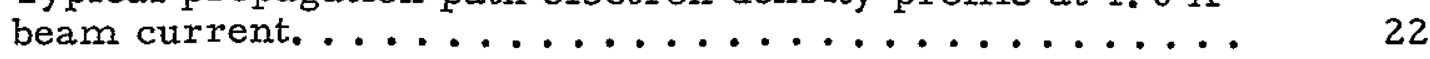

3. Geometry of the transmission model $\ldots \ldots \ldots \ldots . \ldots \ldots 23$

4. Ion thruster test chamber .............. 23 
5. Support ring for microwave absorber. . . . . . . . . . 24

6. Thruster functional diagram ................ 24

7. Measurement equipment configurations .......... 25

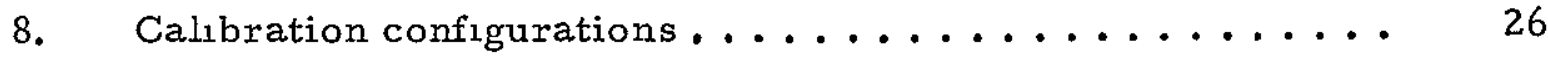

9. Relative signal amplitude vs S-band frequency, E-vertical

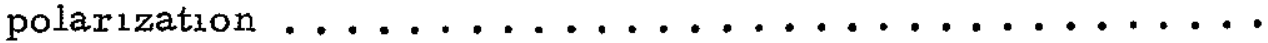

10. Relative signal amplitude vs S-band frequency, E-horizontal

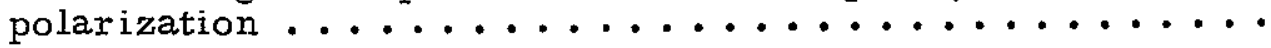

11. Relative signal amplitude vs time, low power, E-vertical

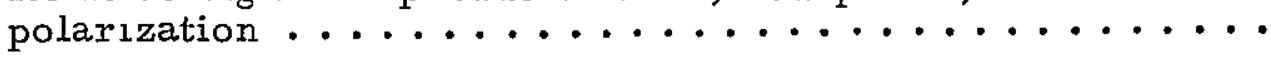

12. Relative signal phase vs time, low power, E-vertical

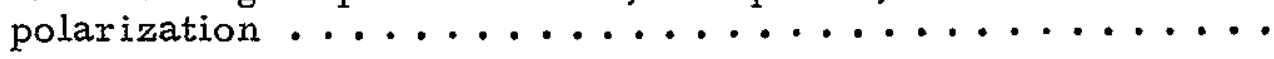

13. Relative signal amplitude vs time, low power, E-horizontal

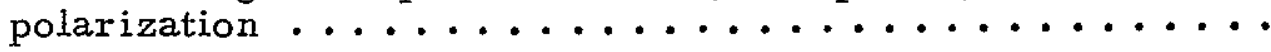

14. Relative signal phase vs time, low power, E-horizontal

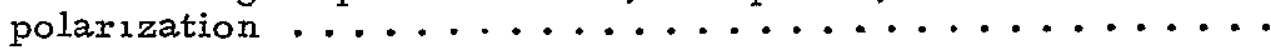

15. Relatıve signal amplitude vs tıme, high power, E-horizontal

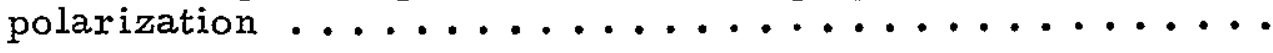

16. Relative signal phase vs time, high power, E-horizontal

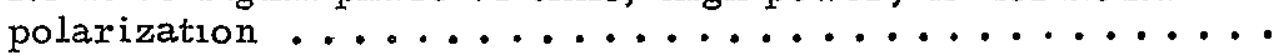

17. Relative signal amplitude calibration vs time, low power .. ' 31

18. Relative signal phase calibration vs time, low power .... 31

19. Distr ibutions of signal amplitude samples, low power,

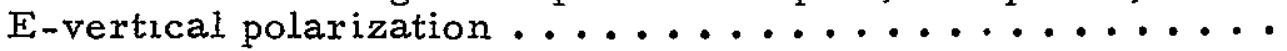

20. Distributions of signal phase samples, low power, E-vertical

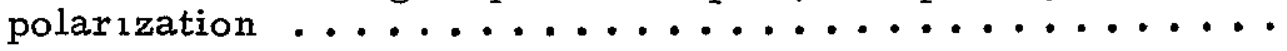

21. Distributions of signal amplitude samples, low power,

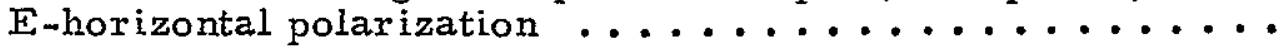

22. Distributions of signal phase samples, low power, E-horizontal

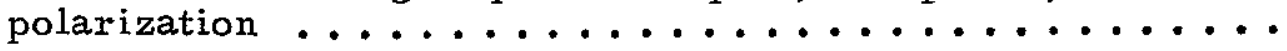

23. Distributions of signal amplitude samples, high power,

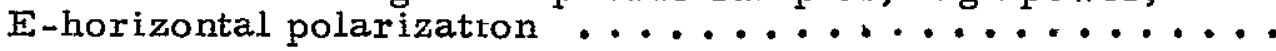

24. Distributions of signal phase samples, high power, E-horizontal

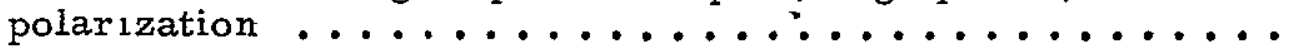


25. Low-frequency spectra of signal amplitude, low power,

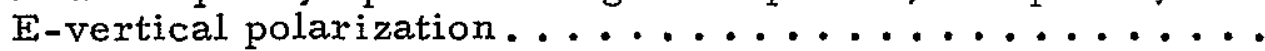

26. Low-frequency spectra of signal phase, low power, E-vertical

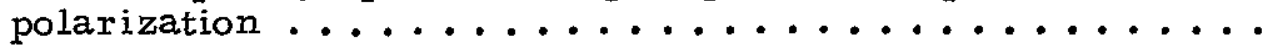

27. Low-frequency spectra of signal amplitude, low power, E-horizontal polarization

28. Low-frequency spectra of signal phase, low power, E-horizontal

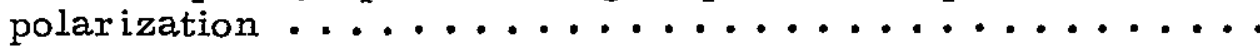

29. Low-frequency spectra of signal amplitude, high power,

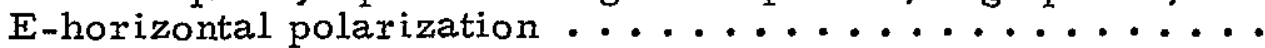

30. Low-frequency spectra of signal phase, high power, E-horizontal

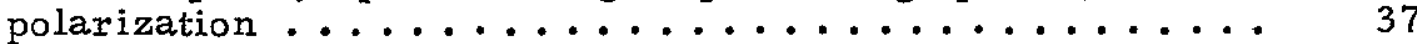

31. Signal phase shift, measured and calculated........ 38

B-1. Transmit and receive antennas ............... 52

C-1. Absorber pumpdown test pressure profiles.......... 54 


\begin{abstract}
The development of electric propulsion for spacecraft applications introduces a plasma medium which may affect the spacecraft-Earth S-band communication system. The objectives of the study reported here are (1) to measure the order of magnitude of the effects of an ion-thruster plume on S-band signals, and (2) to develop modeling techniques to predict the effects.

The measured results show that the RF signal transmitted through an ion-thruster plume is reduced in amplitude and shifted in phase. Both the signal amplitude and signal phase experience a significant increase in noise when passing through the plume. For beam currents between 1. $0 \mathrm{~A}$ and 1. $7 \mathrm{~A}$, the measured loss was between about $-0.3 \mathrm{~dB}$ and $-1.3 \mathrm{~dB}$ and the measured phase shift was between about $20^{\circ}$ and $45^{\circ}$. Many of the experimental problems encountered were not correctable during the short measurement period, so part of this report presents suggestions for the follow-up measurement program.
\end{abstract}




\section{INTRODUCTION}

The development of electric propulsion for spacecraft applications introduces a plasma medium which may affect the spacecraft-Earth communication system. There are times during an electric propulsion mission when the communication path will pass through the exhaust plume of the propulsion engines. Deep space communication links use S-band frequencies, but few ion-thruster experimental plasma studies have been made in this frequency band. Thus, the interaction between the exhaust plasma and an S-band signal is not easily predictable. The study reported here was undertaken to determine the order of magnitude of the effect which an exhaust plasma has on an S-band signal, but not to characterize the engine exhaust plasma. The objectives of the study are (1) to measure the order of magnitude of the effects of an ionthruster plume on S-band signals, and (2) to develop modeling techniques to predict the effects. This investigation was designed to be a preliminary study of a complex problem and to establish the need for more detailed research. Many of the experimental problems encountered were not correctable during the short measurement period, so part of this report presents suggestions for the follow-up measurement program.

The propulsion engine is a mercury ion thruster which is being tested at the Jet Propulsion Laboratory [1]-[3]. 


\section{ANALYTICAL MODEIS}

There are three mechanisms which describe the effects of the exhaust plume on a transmitted signal. The signal may be reflected by the plume, and there may be both transmission loss* and phase shift as the signal passes through the plume. The radio frequency ( $R F$ ) wave/plume interaction depends on many factors such as geometry, RF power density, RF frequency, static magnetic field intensity, particle collision frequency, electron density, ion density, and ion mass.

\section{A. ASSUMPTIONS}

The following assumptions simplify the interaction modeling by reducing the number of factors involved.

\section{Electron Plasma}

The RF wave propagation is affected only by electrons in the plume. The RF interaction with plasma ions is negligible because their mass is relatively large compared with the mass of the electrons. In addition, the RF frequency is much greater than the ion gyrofrequency, and the electron plasma frequency is much greater than the ion plasma frequency (see Appendix A).

\section{Lossless}

The plasma is assumed to produce no absorption loss because the RF frequency is much greater than the effective collision frequency (see Appendix A).

\section{Isotropic}

The plasma is assumed to be isotropic, i. e., the plasma properties are scalar quantities. Reference [4] indicates that a low level of magnetostatic field exists in the plume, so the gyrofrequency of the electrons is small compared to the RF frequency (see Appendix A).

*A loss is always shown as $-X d B$, a negative number. 


\section{Linear}

If the RF power density in the plasma is sufficiently low, the plasma properties are not affected by the RF wave. In this case, the electromagnetic equations are linear equations, and the plasma-induced degradations are independent of the RF power density (see Appendix A);

\section{Adiabatic}

When the plasma characteristics vary slowly near the boundaries, reflection of the RF wave is minimized and the plasma is sald to be "abiabatic." This as sumption is verified in Appendix A.

\section{Permeability}

The permeability of the plasma is assumed to be that of vacuum $\left(4 \pi \times 10^{-7} \mathrm{H} / \mathrm{m}\right)$ because the diamagnetic effect on the permeability is assumed to be small. Using the above assumptions, the following paragraphs descrube the models which are used to obtain first-order estimates of the effects of the plume on the RF signal.

\section{B. PLUME MODEL}

The plume of the 30-centumeter diameter thruster is primarily composed of singly - and doubly-ionized mercury ions with sufficient electrons to neutralize the beam's space charge [5]. Since the RF wave/ion interaction is assumed to be negligible, the electron density distribution is the primary consideration in this modeling. The thruster plume has nearly no net space charge in the region of interest, so the electron density is the sum of the density of singlycharged rons and twice the density of the doubly-charged ions. The charged particle velocities are nearly constant, so the electron density is directly related to the current densities of the ions. The general shape of the plume is that of a cone which is coaxial with the thruster's longitudinal axis

(Figure 1). The electron and ion velocities are on the order of $33 \times 10^{3}$ meters per second [5]. The far field distribution of the lon current is approximated by the following equation (from [6]).

$$
\frac{j(R, \theta)}{\bar{j}}=C\left[\frac{R_{o}}{R}\right] e^{-\left\{k_{1}(1-\cos \theta)\right\}^{k_{2}}}
$$


where $\quad j=$ current density of singly-or doubly-charged ions

$\vec{j}=$ average ion current density at grids

$\mathrm{R}=$ spherical distance from center point of grids

$R_{0}=$ cylindrical radius of thruster grids $(14.75 \mathrm{~cm})$

$\theta=$ spherical angle from thruster centerline

$C, k_{1}, k_{2}=$ constants

A typical electron density profile is shown in Figure 2, which was calculated as shown in Appendix A.

\section{INTERACTION MODEL}

This section describes the changes which occur in an $R F$ wave when it passes through a plasma model described in the previous section. Based on the adiabatic approximation shown in Appendix $A$, the effects of reflections of the RE wave by the plume are not considered in this model.

\section{Phase Shift}

The phase shift of an RF wave in a lossless, adiabatic, linear, 1sotropic, electron plasma may be modeled as the difference in the electrical length of the primary propagation path with and without the plasma present. The phase shift is given in [7] (pg. 120) as

$$
\Delta \phi=\int\left\{1-\left[1-\left(\mathrm{n}_{\mathrm{e}}(\mathrm{x}) / \mathrm{n}_{\mathrm{c}}\right)\right]^{1 / 2}\right\} \frac{2 \pi}{\lambda} \mathrm{dx}
$$

where $\mathrm{n}_{e}(\mathrm{x})$ is the electron density, $\mathrm{n}_{c}$ is the critical electron density defined in [7], and the integral is taken over the primary propagation path which is approximately. a straight line between the transmitting and recerving antennas. If $\mathrm{n}_{\mathrm{e}} \ll \mathrm{n}_{\mathrm{c}}$, the phase shift is approximately

$$
\Delta \phi \underset{n_{e} \ll n_{c}}{\longrightarrow} \frac{\pi}{\lambda n_{c}} \int n_{e}(x) d x \approx \frac{\pi}{\lambda n_{c}} \ell \vec{n}_{e},
$$


where $\bar{n}_{e}$ is the average electron density and $l i s$ the path length in the plasma. Therefore, the phase shift is directly proportional to the average electron density, $\mathrm{n}_{\mathrm{e}}$. The shift is a phase advance because the plasma dielectric constant is less than the free-space dielectric constant.

\section{Transmission}

Under the plasma conditions assumed for the model, there is no transmission loss caused by reflection or absorption. The mechanism for transmission loss is refraction spreading of the RF wave by the plume.

To simplify the calculation of this type of transmission loss, the plume is considered to be a homogeneous plasma having a circular cross section. The geometry is shown in Figure 3. The transmission loss is given by the transmission coefficient, which is the ratio of the received power with the plume present to the received power with the plume absent. For the above case, the transmission coefficient is shown in [7] to be given by

$$
T=\frac{D(L+2 \mathscr{R})}{4 m \mathscr{R}(L+\mathscr{R})+D(L+2 \mathscr{R})}
$$

$$
\text { where } \quad \begin{aligned}
\mathrm{m} & =\frac{1}{\mu}-1=\left(1-\frac{\overline{\mathrm{n}}}{\mathrm{n}_{\mathrm{c}}}\right)^{-1 / 2}-1, \\
\mathrm{D} & =\text { thruster plume model diameter } \\
\mathrm{L} & =\text { effective horn length, } \\
\mathrm{R} & =\text { distance from horn to plume center, and } \\
\mathrm{A} & =\text { antenna aperture height. }
\end{aligned}
$$

Equation II-4 was obtained for D and A much greater than the RF wavelength and with the antennas at least a wavelength from the plume to avoid unduction effects. 


\section{EXPERIMENT}

\section{A. EXPERIMENTAL APPROACH}

The basic approach to this experiment was to mount a transmitting and a receiving $\mathrm{S}-$ band antenna in the con-thruster test chamber and transmit a CW S-band signal through the plasma, recording the amplitude and phase of the received signal during the steady state and transitional thruster operating periods. The results of the measurements are compared with the results of the theoretical models.

In order to obtain meaningful results, the experiment was set up to approximate the theoretical models and to simulate the actual spacecraft configuration while dealing with the physical limitations of the test environment.

\section{B. TEST ENVIRONMENT}

The test chamber was a cylindrical steel vacuum chamber approximately $4.57 \mathrm{~m}$ long by $2.29 \mathrm{~m}$ in diameter (see Figure 4). The thruster was mounted at one end of the chamber and was oriented so that the plume was symmetrical about the chamber's longitudinal axis. The mercury collector and the cylindrical cold liner help maintain the simulated free-space environment. The chamber pressure was on the order of $10^{-4} \mathrm{~N} / \mathrm{m}^{2}\left(10^{-6}\right.$ torr) and temperature was approximately $80^{\circ} \mathrm{K}$ during all of the measurements.

The ideal test environment would be to simulate free space conditions in the test chamber, 1. e., removing electromagnetic reflections and other extraneous effects. The steel walls of the vacuum chamber reflect $R F$ waves and render the free space approximation invalid. Therefore, microwave absorber material was mounted in the chamber to reduce the reflections.

Although actual spacecraft configurations may put the plasma in the nearfield of the antenna, the plasma should be in the antenna far-field to sumplify the analysis. In this experiment the center of the plasma column was approximately in the antenna far-field (see Appendix A), so the space limitation within the tank was not detrimental to the simulation. 


\section{EQUIPMENT}

\section{Antennas}

Two light-weight aluminum, linearly polarized, rectangular, S-band horns (16-dB gain) with fiberglass windows were mounted in the tank as shown in Figure 4 (see Append1x B). The antenna mounts were adjustable for path alignment and for changing polarization. The antennas were vented by a number of holes in the flare walls. The holes were covered with a conductive wire mesh to minimize $R F$, perturbations while maintaining reasonable pumpdown characteristics of the vacuum chamber. The antennas were connected to the test instrumentation by coaxial cables (RG 142 and RG 214) v1a sealed feedthrough connectors on the chamber access ports.

The antennas were mounted and aligned to obtain a propagration path which intersected the plume axis at approximately $30^{\circ}$ (Figure 4) This configuration was selected using the followng considerations:

(a) Maximize the length of the propagation path within the plume, .

(b) Minimize plume impingement on the antennas,

(c) Approximate the position of an antenna on a space vehicle, and

(d) Keep the plume in the transmitting antenna far-field.

Other restrictions included the availability of access ports and mounting fixtures in the chamber, and the close proxumity of the thruster to the lower antenna. The final configuration gave a reasonable simulation while meeting the above criteria.

\section{Absorber}

Preliminary transmission measurements in the steel-walled vacuum tank produced $R F$ power variations of approximately $13 \mathrm{~dB}$ as the frequency was swept (2. 1-2.3 GHz). These large variations indicated the presence of large reflected signals within the tank. Preliminary measurements and analyses showed that the reflections could be reduced significantly by placing a ring of microwave absorbing material between the two antennas. The hole in the ring was large enough to allow nearly all of the exhaust plume to pass through the 
ring unimpeded. Vacuum tests (see Appendix C) of microwave absorbers led to the selection of a flexible, urethane foam-based absorber manufactured by Rantec. This material is not treated with fire retardant or other volatile materials. Fuberglass laminate was epoxied to the backs of the absorber pieces to protect them from stainless steel back splatter and to facilitate mounting. The absorber-f1berglass sections were clip-mounted to a vented aluminum tube frame which was constructed to support the absorber panels as shown in Figure 5. The frame was then installed in the tank as shown in Figure 4.

\section{Instrumentation}

The basic test instrument used in these measurements was a network analyzer. This device compares the signal under test with a reference signal, and it provides output voltages which indicate the relative power (amplitude) difference and the relative phase dufference between the test and reference signals. The output voltages were amplified and transmitted over cables from the test chamber (Bldg. 192) to the recording site (Bldg. 161), a distance of about 250 meters. At the recording site, the signals were sampled, digitized, and recorded on magnetic tape by an XDS 930 computer. The data sampling/ recording system was the same equipment used for the Mariner $10 \mathrm{X}$-band telemetry experiment [8].

The equipment list is given in Appendix D.

\section{Thruster .}

This section describes the thruster characteristics which are pertinent to the experiment. The thruster is a $30-\mathrm{cm}$ mercury electron bombardment ion thruster which was developed at Hughes Research Laboratories [1] - [3]. A functional diagram is shown in Figure 6. Liquid mercury propellant is vaporized in the main feed system and in the discharge cathode feed system. The discharge feed system ionizes the mercury vapor in the discharge chamber. The ionized electrons are accelerated by the anode or arc potential and in turn ionize the mercury vapor in the main chamber. The mercury ions diffuse through the screen and are accelerated by the accelerator electrode screen to form the thruster plume. Because the electron mass is much less than. 
the ion mass, the ion plume is unaltered by the infused electrons and the

electron cloud acquires the same profile as the ion plume to form a plasma which has no net space charge.

The engine thrust is proportional to the mass flow rate of vaporized mercury in the plume. Using constant voltages, the thrust is proportional to the ion beam current, or just "beam current. " The beam current and the plasma density are also directly related, so a primary control parameter is the beam current. If the discharge feed system is "on" when the main mercury flow valve is turned off, the accelerator and screen voltages are set to zero. This case will be called the "beam current $=0 \mathrm{~A}$ " case, even though a small amount of mercury vapor is still ionized by the discharge feed system, and the mercury ions diffuse out of the thruster to form a very low velocity neutral plasma. The quiescent operatung condition is obtained by turning off the discharge feed system so that no mercury vapor is formed. See Appendix $E$ for typical thruster parameters.

\section{TEST PROCEDURE}

The tests were designed to measure the effects of the plume on the S-band (2. 1-2. $3 \mathrm{GHz}$ ) signal amplitude and phase during a number of different thruster operating conditions The experments were also designed to study the effects as a function of $R F$ power level, S-band frequency and antenna polarization. The transmission effects were measured at a number of discrete $S$-band frequencies, at two RF power levels, and at two antenna polarizations. A typical test consisted of setting the RF frequency and power level, fixing the antenna polarization and then recording the sampled amplitude and phase voltages at different beam current levels. The recordings were made continuously, during both the steady beam current periods and transitional periods when the beam current was changing. Additional tests were made at fixed beam current levels with fixed antenna polarization and $R F$ power level while the $R F$ frequency was changed. During these tests the network analyzer output voltages were recorded on an analog recorder rather than being sampled and recorded on tape. These analog recordings were used to calibrate the tank effects and to assess the frequency-dependent effects. The transmission/reflection transducer connected to the network analyzer provided measurements of both the transmission and reflection effects during these tests. 
- Discrete frequency, low RF power tests were made with the equipment configured as shown in Figure $7 \mathrm{a}$. At the higher RF power level, the configuration used for transmission measurements is shown in Fig. $7 \mathrm{~b}$.

Three calibration measurements were made to obtain baseline data for later use. First, the antenna cables were connected together inside the test chamber (Figure $8 \mathrm{a}$ ) and a measurement of transmission amplitude vs. frequency $(2.1-2.3 \mathrm{GHz})$ was made with the tank open. This measurement gave the total link loss excluding the antennas and space loss.

The second calibration measures the link characteristics when the antennas were positioned so that the propagation path does not include the beam (Figure 8b). RF transmission vs. frequency (2.1-2.3 GHz) was recorded with the beam on (steady state) and beam off conditions.

The third calibration was made with antennas and absorber in the normal test position (EV polarization). The output voltages were recorded as a function of frequency from 2.1 to $2.3 \mathrm{GHz}$ with the thruster off and no vacuum. The measurement set is shown in Figure $8 \mathrm{c}$. 
IV. RESULTS

\section{A. MODEL RESUITS}

The results described in this Section were obtained by applying the plume model parameters to the equations shown in Section. II. Because the reflection effects were assumed to be insignificant, only the phase shift and' transmission effects were calculated.

\section{Phase Shift}

Phase shift calculations were performed for three beam current levels, 1. 0, 1.5, and 1. 7 amps, based on the equations derived in Section II. These beam current levels correspond to those used during the experimental measurements. A sample calculation is shown in Appendix A. The three calculated phase shifts are $29.4^{\circ}, 43.9^{\circ}$, and $49.7^{\circ}$ for the three beam current levels.

\section{Transmission}

The amplitude transmission loss was calculated at the 1. 0-ampere beam current level (see Appendix A). Because the beam was modeled as a homogeneous cylinder in this case, the cylinder diameter was arbitrarily set at the width of the half-peak level on the electron density profile (see Figure 2). The average electron density between the half-peak points was used to determine the index of refraction of the cylinder. Based on this model, the calculated transmission.loss is $-0.85 \mathrm{~dB}$.

\section{B. EXPERIMENTAL RESULTS}

This section describes the analyses of the amplitude and phase outputs from the network analyzer. These analyses characterize the amplitude and phase properties of the RF signal at the various engine operating conditions. The amplitude and phase voltages were recorded in two different ways. First, for a fixed engine operating condition, the output voltages were recorded on an analog strip chart as the RF frequency was varied from 2.1 to $2.3 \mathrm{GHz}$. These recordings show the effects of reflections in the tank, and they may be compared at different operating conditions to determine the relative changes in signai amplitude. Second, the output voltages were sampled and recorded on 
magnetic tape. The sampled data were recorded at discrete $R F$ frequencies as the engine operating conditions were changed. These measurements were analyzed to display both the time history and the low frequency spectrum of the interaction.

The transmission/reflection transducer allowed reflection measurements to be made easily during the measurement sequence. During the limited test period, the test antennas were not aligned specifically for reflection measurements, and the results of these measurements were used only as an indication of reflection effects. At no time were reflection measurements observed which were considered to be significant. Therefore, no reflection measurements are included in the following Sections.

The calibration of the cables (Figure $8 \mathrm{a}$ ) showed that the cable loss over the frequency range of $2.1-2.3 \mathrm{gHz}$ was between 8.3 and $9.0 \mathrm{~dB}$, which is close to the expected value. This measurement indicated that there was no significant mismatch in the cable path.

\section{Analog Data Analysis}

Analog recordings of the amplitude and phase voltages as a function of $R F$ frequency show nonlinear variations which are caused by reflected signals in the tank. The range of the amplitude signal variations can be used to estimate the reflected signal level. The recordings also can be compared for various operating conditions to determine the average change over the frequency range. Only the amplitude recordings are presented here. The phase measurements displayed poor resolution because of the very large total phase shift across the frequency band.

Figure 9 shows the relative amplitude of the received signal at two different times, before the absorber ring was installed and after the ring was installed. The "after" curves are shown with the beam current at 1.0 amp and with the beam off, discharge on. The figure shows about a 10-dB reduction in the signal variations after the ring was installed. The, reduction is the result of decreasing the reflected signal strength within the tank. If no reflections were present (i.e., free space conditions) the received signal would be approximately constant over the frequency range. 
Figure 9 displays an apparent "frequency shift" in the response. This phenomenon is attributed to the reflections in the tank and should not occur under free space conditions. The "frequency shift" may be understood by considering the electrical path lengths of the direct path and the reflected path. The difference between the two electrical path lengths apparently changes as the beam current changes because of the beam-induced phase shift in each path. Neglecting the amplitude changes due to the beam, the path length difference must be the same to receive a constant signal level. Thus, the operating frequency with the beam on must be changed to obtain the same electrical path length difference that was present when the beam was off. Conversely, the same electrical path length difference apparently occurs at a higher frequency with the beam on than when the beam is off.

The average of the beam-caused change in signal amplitude is the average difference between the beam-on and beam-off curves with the frequency shift removed. In Figure 9, the average loss with the beam on at $1.0 \mathrm{amp}$ is $-0.38 \mathrm{~dB}$ when compared with the beam-off, discharge-on condition. These measurements were made at the low RF power level with the microwave horns polarized in the E-vertical position.

When the polarization of the antennas was changed to the E-horizontal position, the signal amplitude was measured at two RF power levels, as shown in Figure 10. The low power level is the same level at whlch the curves of Figure 9 were measured. At the low power level the average loss at 1.0-amp beam current was calculated as $-0.84 \mathrm{~dB}$ compared with the beam-off, discharge-on mode. The high RF power level showed an average loss of $-0.68 \mathrm{~dB}$ at 1.0 -amp beam current. Both calculations were made with the frequency shift effect removed. The calibration measurements show the frequency shift effect but no difference in level after the shift is removed.

The results illustrated in Figures 9 and 10 show that the 1.0 -amp beam current level causes a loss of less than $1 \mathrm{~dB}$ in the signal amplitude. The differences among the three sets of measurements are considered to be within the measurement accuracy. The observed frequency shift effect must be considered when interpreting data measured at discrete frequencies. 


\section{Sampled Data Analyses}

The amplitude and phase voltage samples show the signal variations as a function of time for discrete $R F$ frequencies. The data samples were processed to obtain the signal statistics and the low frequency spectral response. The signal statistics obtained were (1) the short term sample mean and standard deviation, and (2) the distribution of a large number of samples. These results display the relative shifts in signal amplitude and phase, the changes in noise levels, and the spread of the sample distributions at the various engine operating conditions.

a. Time Averages. Sequences of amplitude and phase samples were processed in five-second groups to obtain the average and standard deviation of each group. The sets of amplitude and phase plots shown he re represent two different RF power levels and two antenna polarizations. Each pair of plots shows the relative amplitude and phase shift as the engine beam current is varied. For example, Figures 11 and 12 display the amplitude and phase, respectively, as the beam current changes from zero amp to one amp and 1.7 amps. Finally, the discharge voltage is turned off so that the quiescent condition is reached. Here the $R F$ power was low and the horn antennas were oriented with the E-polarization vertical. The effects of the various beam current levels are clearly displayed in the figures. The beam causes a substantial drop in the signal level and a moderate advance in phase caused by the decreased electrical path length within the beam. The noise levels, as measured by the standard deviations, are larger when the beam is on. The highest noise level is at 1.0-amp beam current. There is a slight drift in the observed data at the 1.7-amp current level. This was the highest current attainable during the tests, and the engine did not reach steady state during the time period shown. In Figures 11 and 19, the indicated attenuation is greater for the quiescent condition than it is for zero amp beam current, contrary to other single-frequency measurements. This result is apparently caused by the frequency-shift effect discussed in Section IV B1.

Figures 13 and 14 show the results with the RF power low and the antennas oriented E-horizontal. In this case, the beam current varied from 1.5 amps to zero, and no quiescent measurements were made. Again, the beam causes an amplitude drop and a phase advance. The noise level increases with the beam 
on and 1s highest at the 1.0-amp current level. The changes in the signal properties are comparable with those displayed with the horns E-vertical, so the change of horn polarization appears to have little effect on the results.

The third set of curves, Figures 15 and 16, show the results with the horns E-horizontal and the RF power high. Again the signal characteristics are very similar to those shown previously. Thus, there appears to be no significant difference between the two RF power levels.

The last set of curves, Figures 17 and 18, show data recorded during the calibration measurements. The levels are nearly independent of beam current. The small changes are attributed to tank reflection effects rather than to changes in the medium between the antennas. In Figure 18, the phase drift observed during the 45-minute break in the measurement period may have been due to temperature variations in the tank rather than to plume-related effects.

The sampled data were also processed to obtain two-minute statistics. These results are compiled in Table 1. The average values all are referred to the quiescent value, except for the second set of numbers where no quiescent data were recorded. The results show a loss of about -0.3 to $-0.5 \mathrm{~dB}$ at $1 \mathrm{amp}$, -0.7 to $-1.1 \mathrm{~dB}$ at $1.5 \mathrm{amps}$, and about $-1.25 \mathrm{~dB}$ at 1.7 amps. The amplitude standard deviation $1 \mathrm{~s}$ about $0.1 \mathrm{~dB}$ with the beam current on. The phase advance is about $20^{\circ}$ at 1 amp and $35^{\circ}$ at 1.5 amps. The phase noise level is between $1^{\circ}$ and $2^{\circ}$ whenever the engine duscharge voltage is on. Because of the frequency shift effect, the relationship of the results at the various current levels may contain a moderate error since the data were measured at discrete frequencies.

b. Distributions. The statistical distribution of the amplitude and phase samples displays additional information about the effects of the plasma medium on the communication link. The distributions were obtained by counting the number of samples at each digital level and then normalizing with respect to the total sample count. The sample densities shown in Figures 19 and 20 represent 24,000 samples per curve taken with the horns E-vertical and low RF power. These sample sets were obtained from the data shown in Figures 11 and 12 and tabulated in Table 1 . The average values of the quiescent amplitude and phase distributions are used as the zero reference level in each 
case. A shift of the distribution center indicates a change in average level, while a larger spread of the distribution is the result of a higher noise level. The distributions are, in general, symmetric and have the statistics shown in Table 1. Figures 21 and 22 show the normalized densities of 12,000 samples per curve when the horns were E-horizontal with low RF power. In this case, the distributions use the zero-amp beam current average levels as the reference because no quiescent measurements were made. The distributions for the E-horizontal, high RF power case are shown in Figures 23 and 24 . The distributions are all nearly symmetric and display the noise level as being the highest at $1.0 \mathrm{amp}$ beam current.

c. Spectral Analysis. Time sequences of the data samples were input to a Fast Fourier Transform routine to obtain the low frequency spectra of the sequences. The spectra display the level and the bandwidth of the RF noise interference produced by the engine beam. The FFT routine accepts $2^{\mathrm{N}}$ samples ( $N$ an integer) of amplitude or phase data and provides the Fourier sine and cosine coefficients, $a_{k}$ and $b_{k}$, at frequencies $\omega_{k}=2 \pi k / T$, where $T$ is the period of the $2^{\mathrm{N}}$ samples. The results shown here are power spectral densities, $c_{k}^{2}=a_{k}^{2}+b_{k}^{2}$. Each curve is the average of the spectra from four consecutive sets of 2048 samples $(N=11)$, with the resulting average spectrum $(60-\mathrm{Hz}$ component removed) smoothed by using a 20 -point moving average.

The spectra shown in Figures 25 and 26 were obtained from data measured with the horns E-vertical and low RF power. The curves show that the noise is uniformly distributed in the band of $1-100 \mathrm{~Hz}$. The noise power level (both amplitude and phase) is highest at the 1.0-amp beam current level and about an order of magnitude lower in power with the beam current off. The spectra for the horns E-horizontal, low RF power (Figures 27 and 28) and high $R F$ power (Figures 29 and 30 ) are plotted to $10 \mathrm{~Hz}$ because the sample rate was $1 / 10$ the sample rate used for the first spectral set. These plots show that the noise power is nearly uniform except at the very low frequency end of the band. However, the large low-frequency components may result from inaccuracies in the FFT analysis.

For a given beam current, the three sets of spectra show that the amplitude noise power or phase noise power is within a factor of 2 , independent of the antenna orientation and RF power level. The l-amp beam current level 
produces the most noise, and 1.5 - 1.7 amps produce about half as much noise power. In all cases except one, the zero-amp noise level is much less than when the beam current is on.

\section{Measurement Summary}

The set of results presented here shows a consistent trend and also points to areas where followap measurements can improve the quantitative concluslons. The analog recordings of the signal amplitude show an average loss at the 1. 0 -amp beam current of -0.4 to $-0.8 \mathrm{~dB}$ in the $R F$ frequency range of $2.1-2.3 \mathrm{GHz}$. This loss is comparable to the loss for discrete frequencies obtained from the sampled data. The sampled data also show a loss of about -0.75 to $-1.1 \mathrm{~dB}$ at the 1.5 -amp beam current and about $-1.25 \mathrm{~dB}$ at the 1. 7-amp beam current. The sampled data also reveal that the amplitude noise level is the highest at the 1.0-amp beam current. The phase advance at $1.0 \mathrm{amp}$ is about $15^{\circ}$ compared with the 0 -amp case, while the advance is about $30^{\circ}$ at 1.5 amps and $35^{\circ}$ at 1.7 amps. The phase no1se level is also the highest at the 1.0-amp beam current. When the thruster is on, the amplitude and phase noise levels are, in general, lower for higher beam currents. This result is not explainable at the present time. The results are relatively insensitive to the antenna polarizations and to the RF power level used in this experiment. The reflected signals in the tank cause an apparent frequency shift which produced uncertainties in the data measured at discrete frequencies. Followup measurements could reduce the single-frequency uncertanties by compensating for the frequency shift effect and reducing the reflection level.

\section{COMPARISONS}

In general the measured effects were slightly less than the calculated effects. The measured and calculated values of phase shift are shown in Figure 31 for three levels of thruster beam current. The measured values shown were obtained from Table 1. The curves show that the measured values are about $6-8^{\circ}$ below the calculated values. No confurmed source of this "bias" difference has been established, but the difference is well within model inaccuracies and measurement uncertainties. 
The transmission loss at 1.0-amp beam current was calculated as $-0.85 \mathrm{~dB}$ compared with an average measured value of about $-0.63 \mathrm{~dB}$ from Figures 9 and 10. The average loss from Table $I$ is about $-0.43 \mathrm{~dB}$. Again these values compare favorably when considering the model inaccuracies, the measurement uncertainties and data resolution. 


\section{CONCLUSIONS}

The major objectives of this study were (1) to measure the order of magnitude of the effects of an ion thruster plume on S-band signals, and (2) to develop modeling techniques to predict the effects. The results show that the study objectives have been accomplished.

The measured results show that the RF signal transmitted through an ion thruster plume is reduced in amplitude and shifted in phase. Both the signal amplitude and signal phase experience a significant increase in noise when passing through the plume. For beam currents between $\dot{1} .0$ and 1.7 amps the measured transmission loss was between about -0.3 and $-1.3 \mathrm{~dB}$. The measured phase shift was between about $20^{\circ}$ and $45^{\circ}$. The signal amplitude maximum RMS noise level was about $0.1 \mathrm{~dB}$ while the maximum RMS noise level of the signal phase was about $2^{\circ}$. When the thruster is on, the amplitude and phase noise levels are, in general, lower for higher beam currents.

The models and assumptions were developed to obtain a rough estimate of the transmission loss and phase shift. The calculated loss and phase shift were slightly higher than the measured values. Even with the simplicity of the models, the accuracy of the predictions was well within the expectations of the experimenters. The transmission loss model can be improved significantly by using a concentric cone plume model and then using elliptic cross sections to account for the angle between the RF path and the plume centerline.

A report [9], obtained at the end of the report preparation, revealed a potential degradation condition not anticipated by the experimenters. At small angles between the RF path and the plume centerline, RF ray refraction may be such that some rays are bent away from the plume. In this case, a region may exist into which no communication is possible. Further study is required before this condition can be defined more clearly.

At the beginning of the study, preliminary calculations indicated that some transmission loss and phase shift would be measurable. However, the effects of the test tank on the measurements could not be estimated. Preliminary measurements revealed that, in fact, there were measurable effects, including an increase in $R F$ noise when the thruster was operating. 
Swept frequency measurements also displayed the presence of strong multipath signals in the tank. This problem was substantially solved by the ring of microwave absorber. With the reflection problem reduced by the absorber ring, the swept frequency measurements were useful in removing some of the reflection effects from the amplitude data. The benefit of this measurement procedure was realized only at the end of the test sequence, and time did not permit the construction of an accurate swept-frequency measurement setup. Thus, only a few swept-frequency measurements were possible.

Two operational improvements could significantly reduce uncertainties and improve the efficiency of the experiment. First, the antenna orientation changes should be possible from outside the tank. Considerable time was lost each test day because the tank had to be opened to change the antenna polarization. Time is lost when a man must enter the tank because of the severe precautions which are required to prevent contamination from the mercury residue in the tank. Also, it takes about two hours to pump down the tank after it has been opened. Thus, about three extra hours of measurements could be made each day if the antenna orientation can be made from outside the tank.

Second, automatic time recording should be included both on the thruster parameter recordings and on the $R F$ measurement recordings. This simple addition would greatly reduce the postmeasurement problems of correlating the thruster and RF operating conditions. 
Table 1. Two-minute average, signal amplitude and phase changes at various thruster operating current levels. All average values are relative to the quiescent value, except as noted.

\begin{tabular}{|c|c|c|c|c|c|c|c|c|c|c|c|}
\hline \multirow{3}{*}{$\begin{array}{l}\mathrm{RF} \\
\text { mode }\end{array}$} & \multirow{3}{*}{$\begin{array}{c}\text { Output } \\
\text { parameter }\end{array}$} & \multicolumn{10}{|c|}{ Thruster mode } \\
\hline & & \multicolumn{2}{|c|}{ Quiescent ${ }^{1}$} & \multicolumn{2}{|c|}{$0 \operatorname{amp}^{1}$} & \multicolumn{2}{|c|}{1 amp } & \multicolumn{2}{|c|}{$1.5 \mathrm{amps}$} & \multicolumn{2}{|c|}{1.7 amps } \\
\hline & & Ave & $\sigma$ & Ave & $\sigma$ & Ave & $\sigma$ & Ave & $\sigma$ & Ave & $\sigma$ \\
\hline $\begin{array}{l}\text { Low Power } \\
\text { E-Vertical } \\
\mathrm{f}=2.20 \mathrm{GHz}\end{array}$ & $\begin{array}{l}\text { Amplitude } \\
\text { (dB) } \\
\text { Phase } \\
\text { (deg) }\end{array}$ & $\begin{array}{l}0 \\
0\end{array}$ & $\begin{array}{l}0.04 \\
0.17\end{array}$ & $\begin{array}{l}0.19 \\
7.36\end{array}$ & $\begin{array}{l}0.05 \\
1.05\end{array}$ & $\begin{array}{l}-0.34 \\
21.85\end{array}$ & $\begin{array}{l}0.12 \\
1.46\end{array}$ & $\begin{array}{l}-1.09 \\
39.10\end{array}$ & $\begin{array}{l}0.12 \\
1.14\end{array}$ & $\begin{array}{l}-1.28 \\
43.66\end{array}$ & $\begin{array}{l}0.10 \\
0.94\end{array}$ \\
\hline $\begin{array}{l}\text { Low Power } \\
\text { E-Horiz. } \\
\mathrm{f}=2.21 \mathrm{GHz}\end{array}$ & $\begin{array}{l}\text { Amplitude } \\
\text { (dB) } \\
\text { Phase } \\
\text { (deg) }\end{array}$ & $\begin{array}{l}-2 \\
-2\end{array}$ & & 0 & $\begin{array}{l}0.05 \\
0.98\end{array}$ & $\begin{array}{l}-0.30 \\
15.48\end{array}$ & $\begin{array}{l}0.11 \\
2.04\end{array}$ & $\begin{array}{l}-0.73 \\
28.88\end{array}$ & $\begin{array}{l}0.09 \\
1.27\end{array}$ & - & \\
\hline $\begin{array}{l}\text { High Power } \\
\text { E-Horiz. } \\
\mathrm{f}=2.21 \mathrm{GHz}\end{array}$ & $\begin{array}{l}\text { Amplitude } \\
\text { (dB) } \\
\text { Phase } \\
\text { (deg) }\end{array}$ & $\begin{array}{l}0 \\
0\end{array}$ & $\begin{array}{c}0.02 . \\
0\end{array}$ & $\begin{array}{r}-0.11 \\
6.83\end{array}$ & $\begin{array}{l}0.04 \\
0.90\end{array}$ & $\begin{array}{l}-0.50 \\
21.34\end{array}$ & $\begin{array}{l}0.12 \\
1.52\end{array}$ & $\begin{array}{r}-1.09 \\
34.47\end{array}$ & $\begin{array}{l}0.09 \\
1.25\end{array}$ & $\begin{array}{l}- \\
-\end{array}$ & \\
\hline $\begin{array}{l}\text { Calibration } \\
\text { Low Power } \\
\mathrm{f}=2.145 \mathrm{GHz}\end{array}$ & $\begin{array}{l}\text { Amplitude } \\
\text { (dB) } \\
\text { Phase } \\
\text { (deg) }\end{array}$ & $\begin{array}{l}0 \\
0\end{array}$ & $\begin{array}{r}0.03 \\
0\end{array}$ & $\begin{array}{l}-0.03 \\
22.43\end{array}$ & $\begin{array}{l}0.03 \\
0.39\end{array}$ & $\begin{array}{l}-0.11 \\
18.85\end{array}$ & $\begin{array}{r}0.02 \\
0\end{array}$ & $\begin{array}{l}-0.20 \\
20.94\end{array}$ & $\begin{array}{r}0.03 \\
0\end{array}$ & $\begin{array}{l}- \\
-\end{array}$ & \\
\hline
\end{tabular}

${ }^{1}$ Quiescent mode $=$ current off, discharge voltage off; 0 amp = current off, discharge on.

${ }^{2}$ No quiescent measurements were made in this mode. 


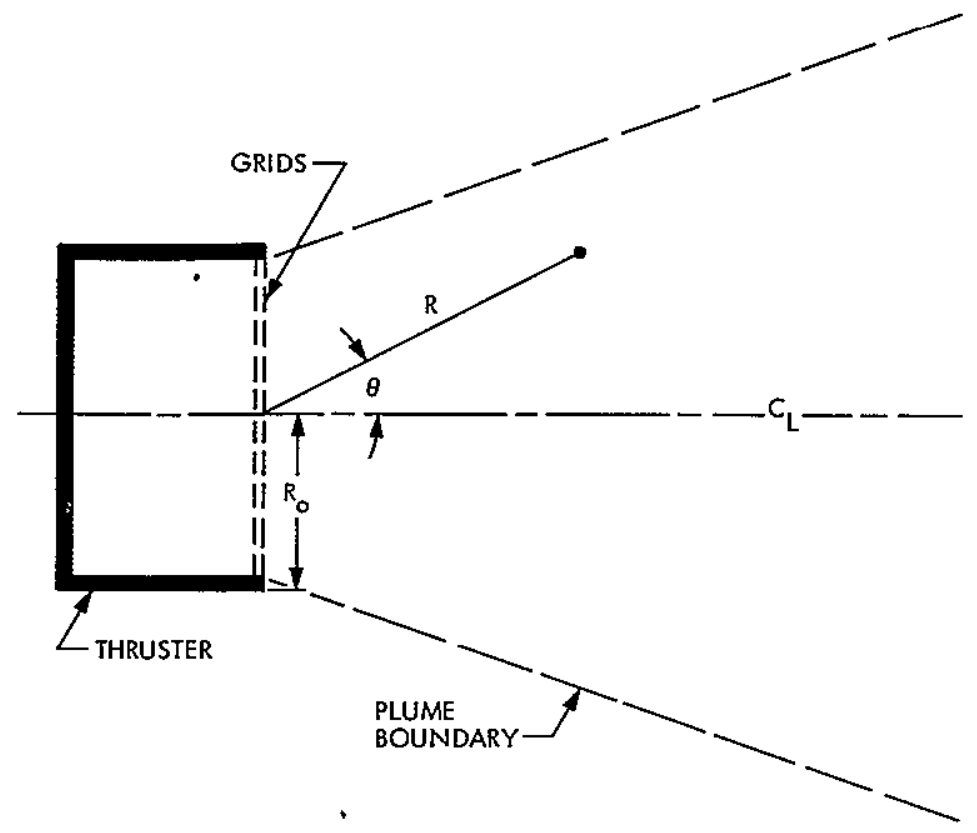

Fig. 1. Geometry of the plume model

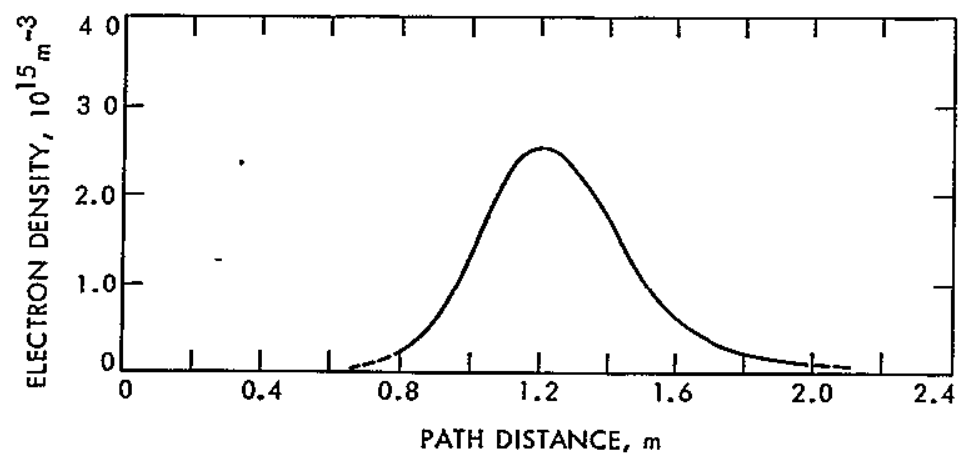

Fig. 2. Typical propagation path electron density profile at $1.0 \mathrm{~A}$ beam current 


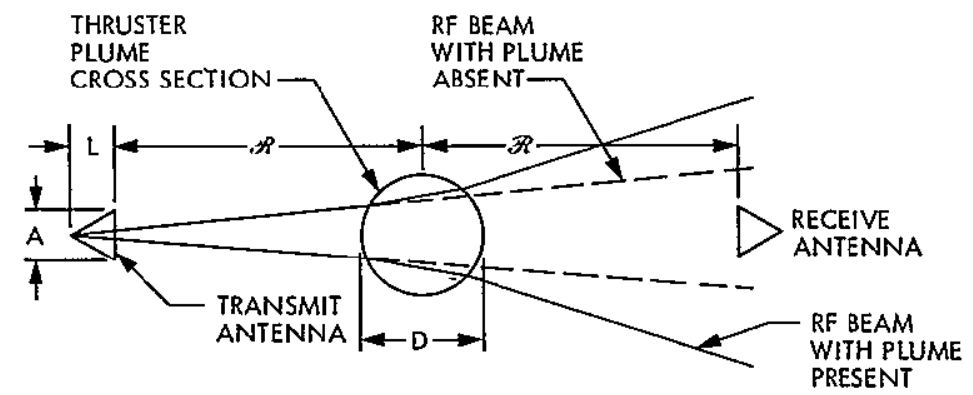

Fig. 3. Geometry of the transmission model

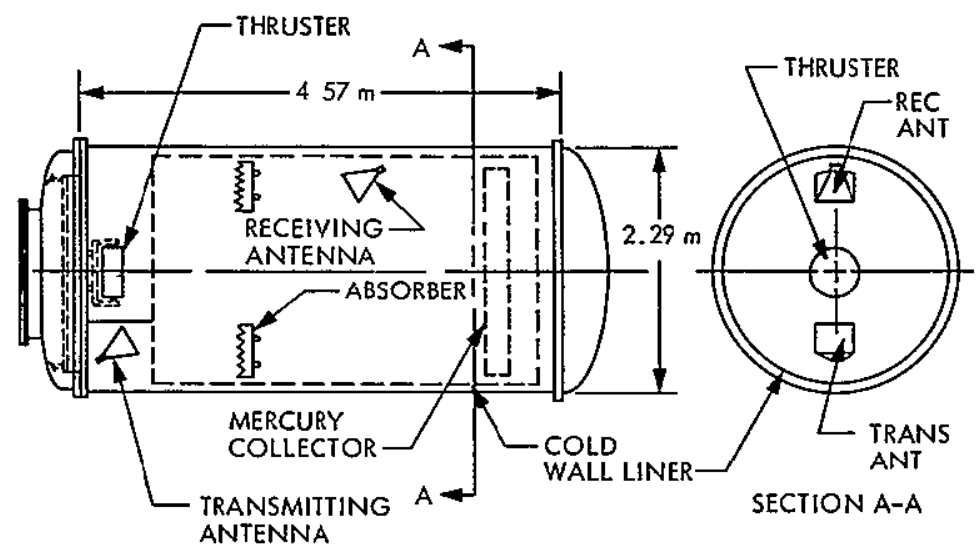
(a) SIDE VIEW
(b) END VIEW

Fig. 4. Ion thruster test chamber 


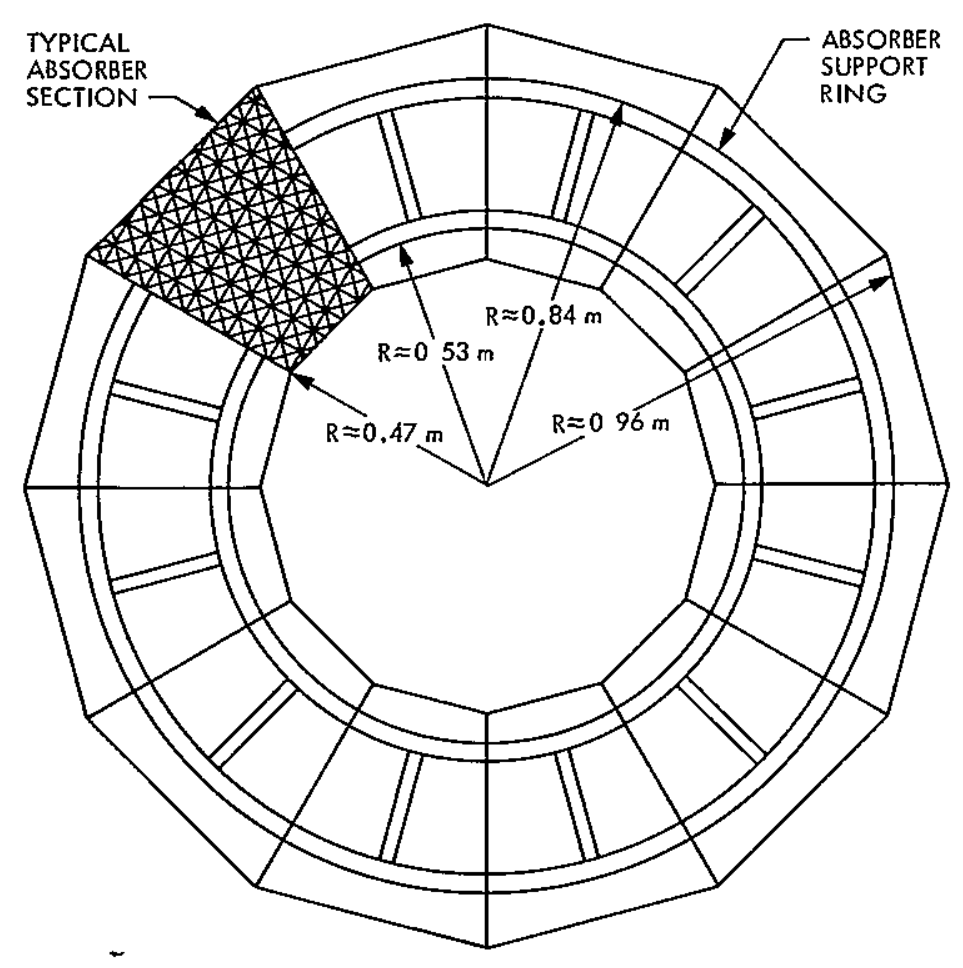

F1g. 5. Support ring for microwave absorber

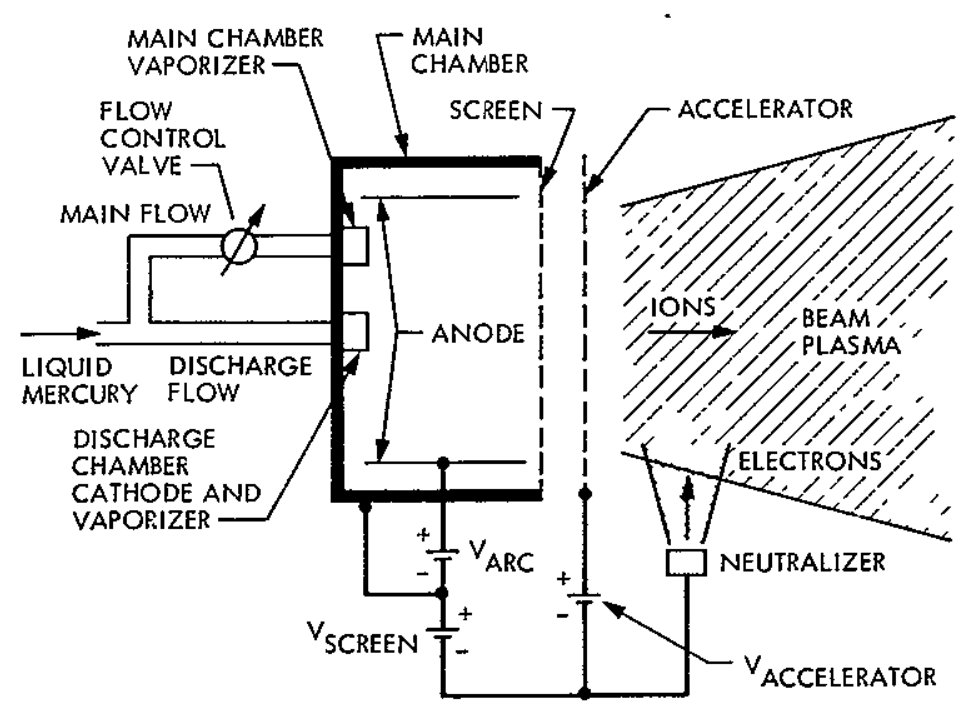

Fig. 6. Thruster functional diagram 
(a) LOW POWER TRANSMISSION AND REFLECTION MEASUREMENTS

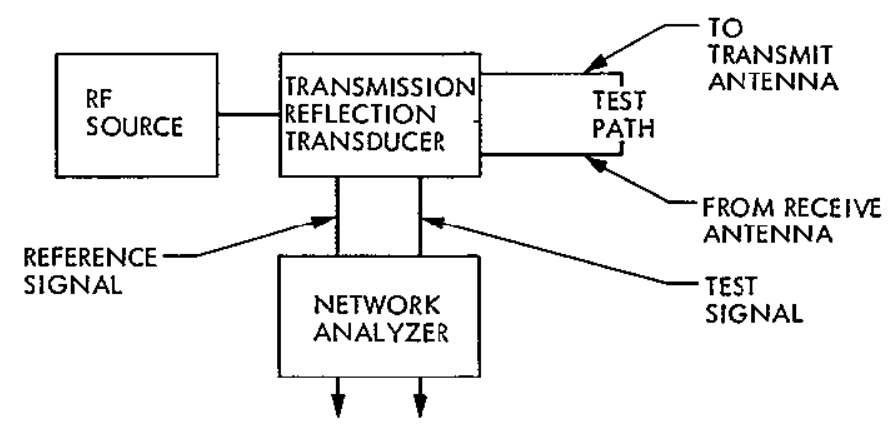

TO RECORDING EQUIPMENT

(b) HIGH POWER TRANSMISSION MEASUREMENTS

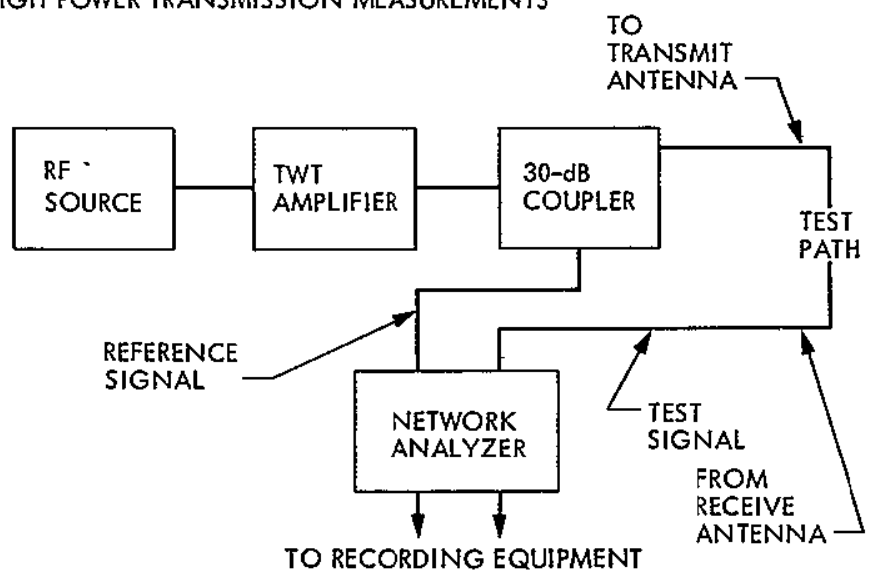

Fig. 7. Measurement equipment configurations 
(a) CABLE CALIBRATION

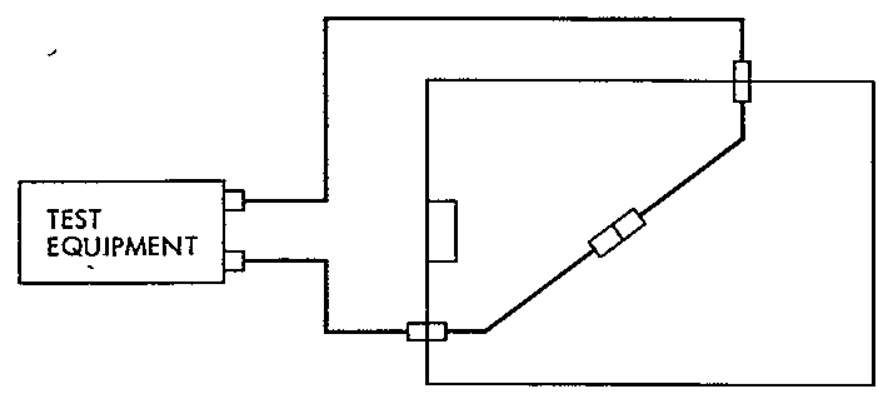

TEST CHAMBER

(b) BACKGROUND CALIBRATION

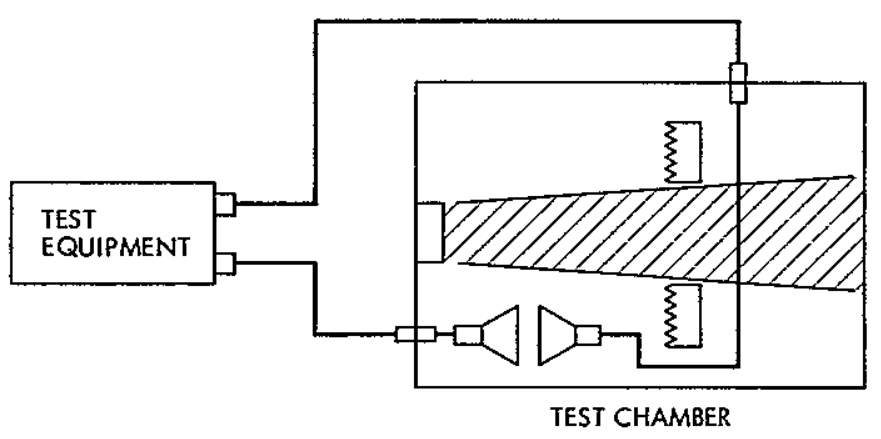

(c) BASELINE CALIBRATION

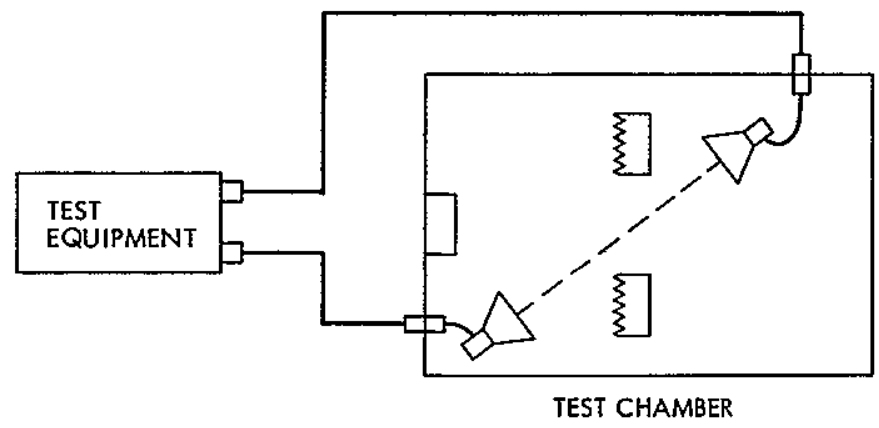

Fig. 8. Calibration configurations 


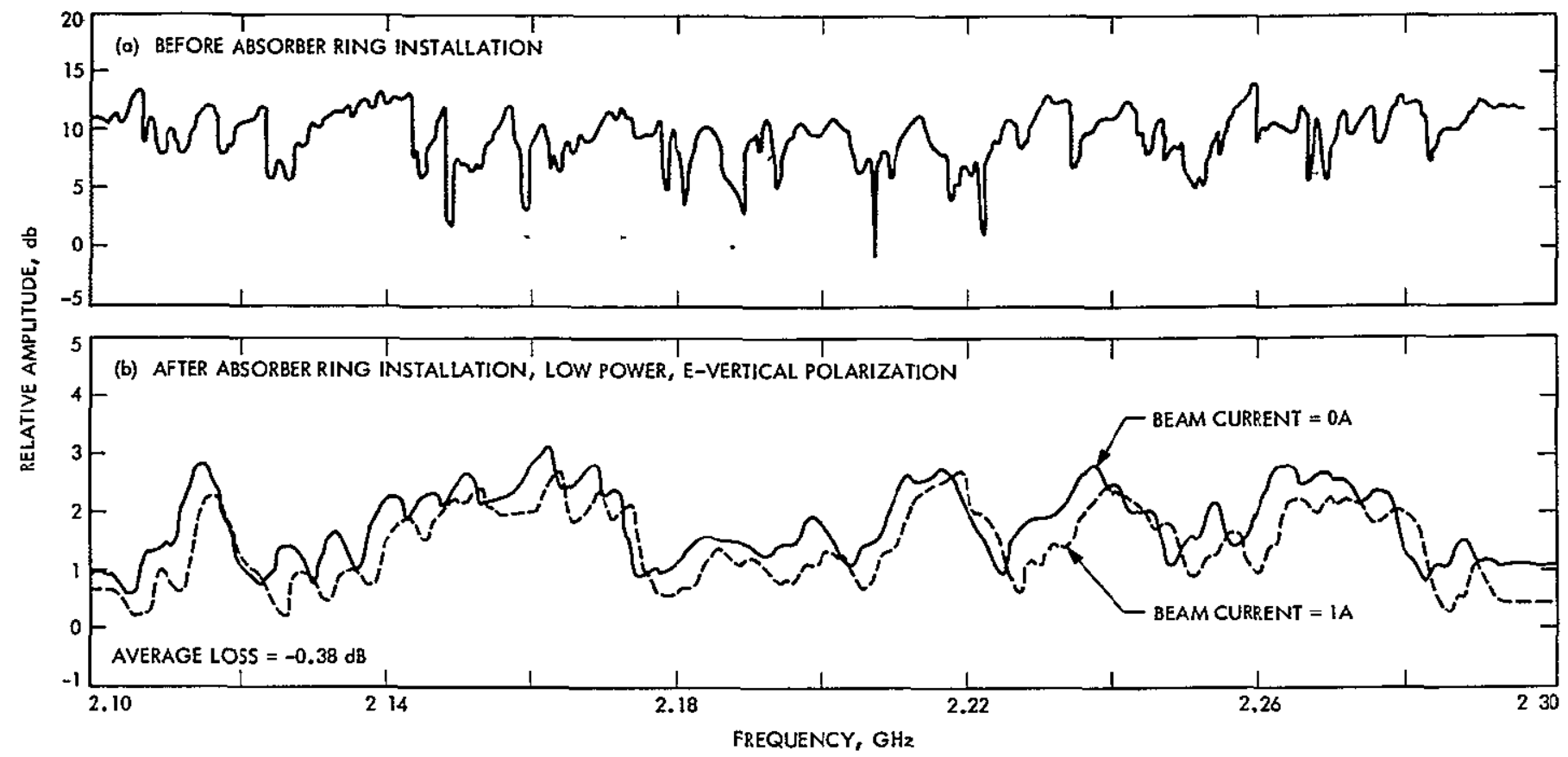

Fig. 9. Relative signal amplitude vs S-band frequency, E-vertical polarization
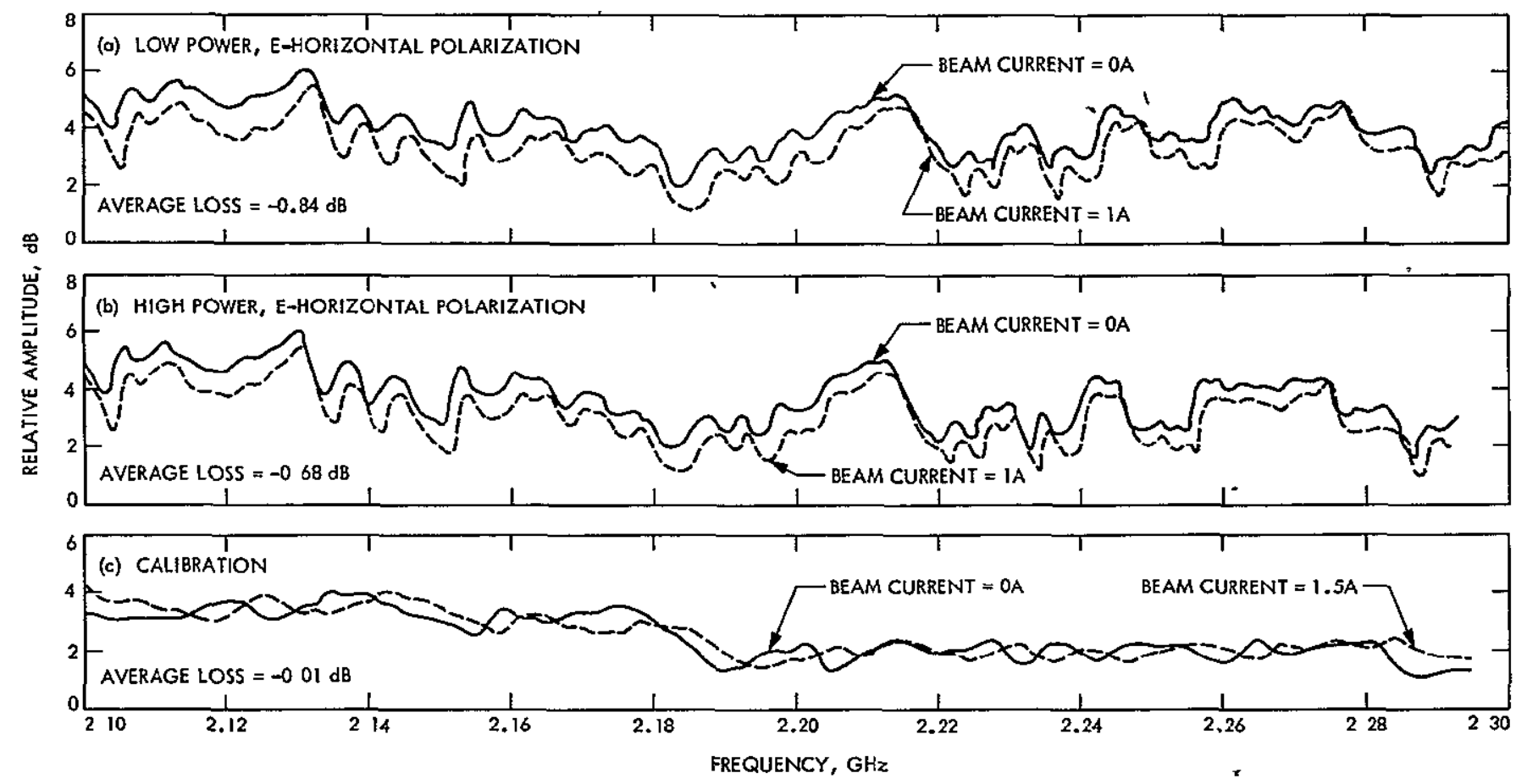

Fig. 10. Relative signal amplitude vs S-band frequency, E-horizontal polarization 


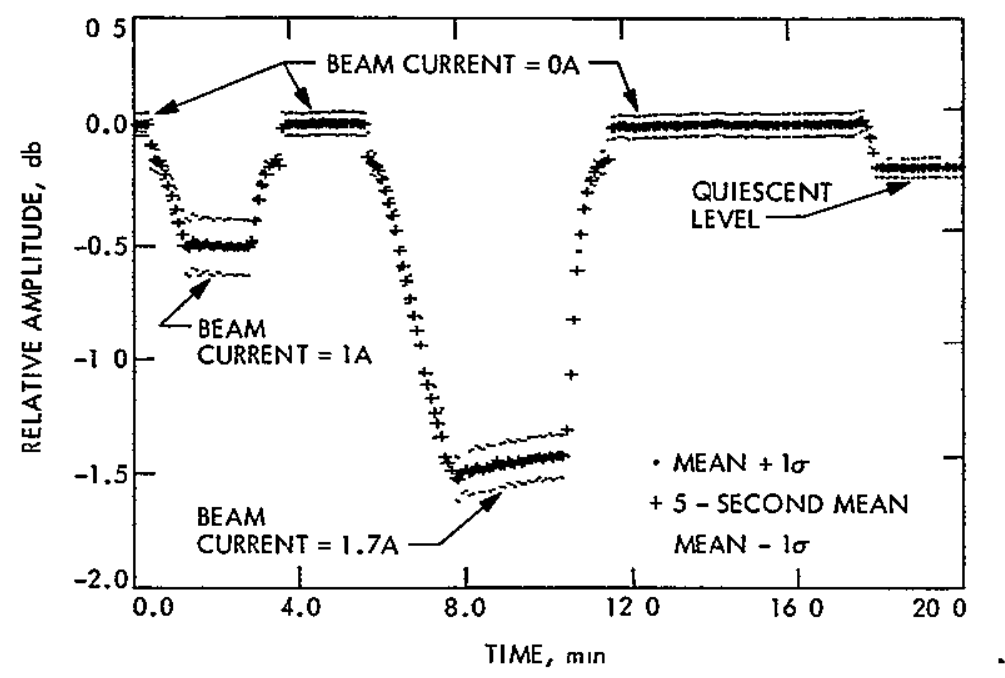

Fig. 11. Relative signal amplitude vs time, low power, E-vertical polarization

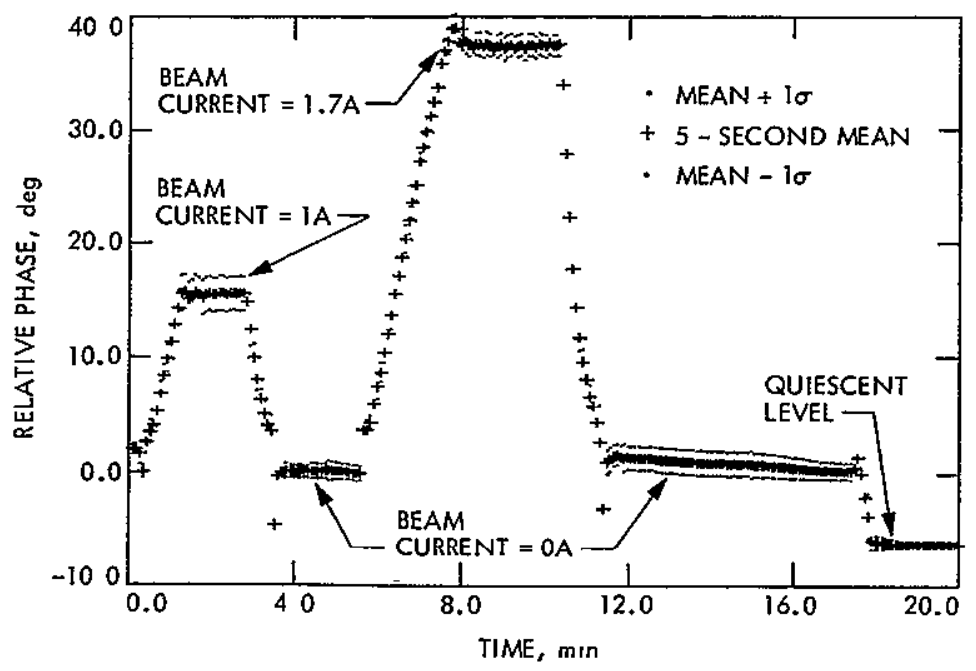

Fig. 12. Relative signal phase vs time, low power, E-vertical polarization 


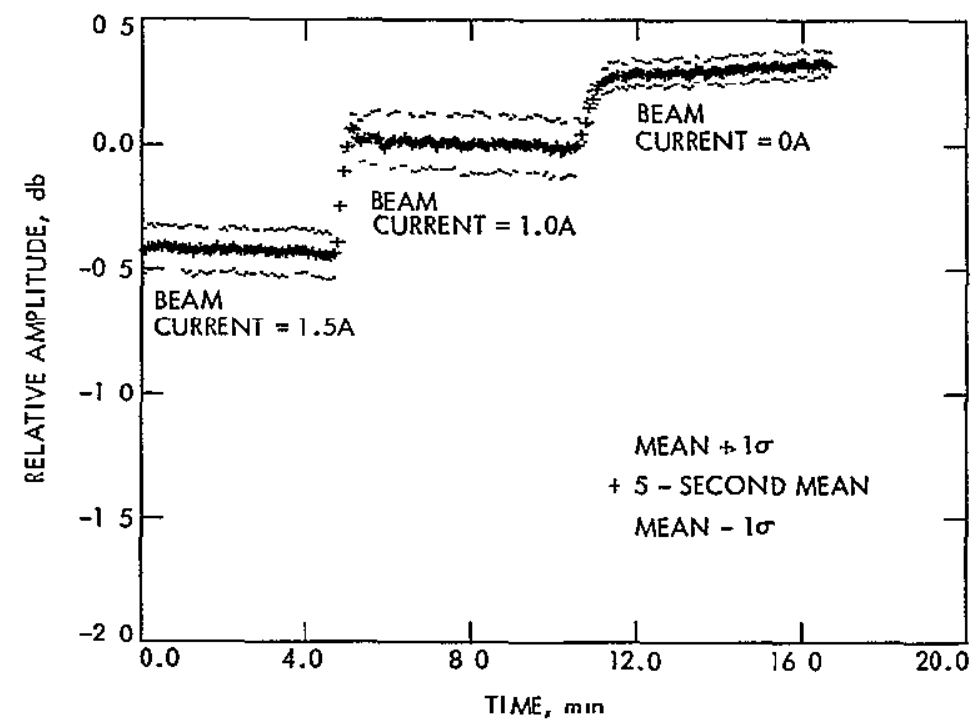

Fig. 13. Relative signal amplitude vs time, low power, E-horizontal polarization

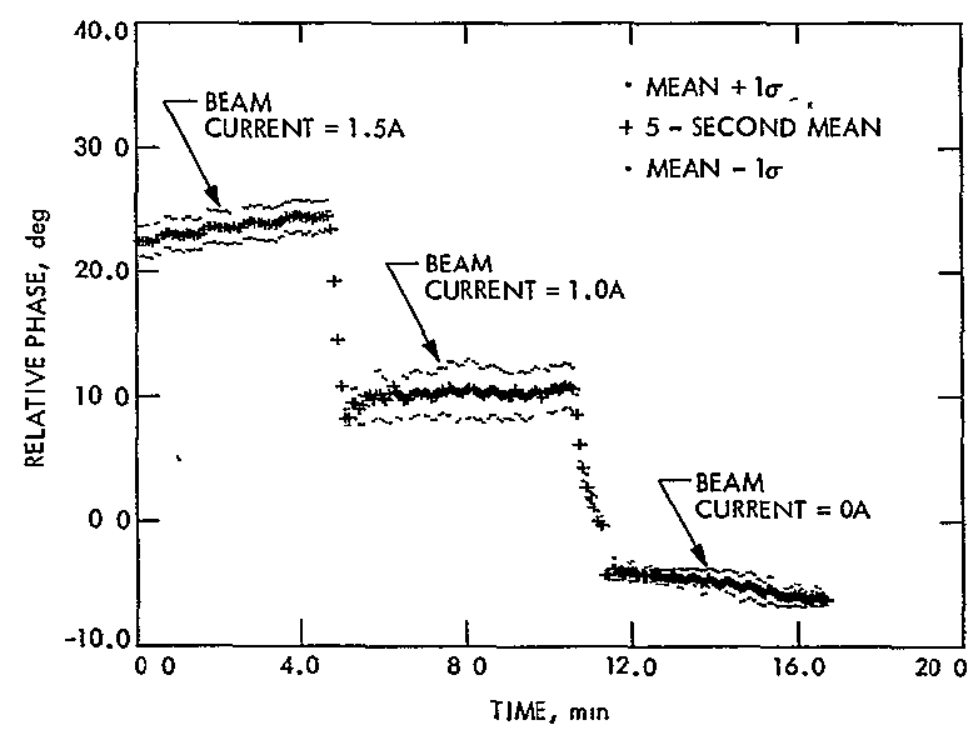

Fig. 14. Relative signal phase vs time, low power, E-horizontal polarization 


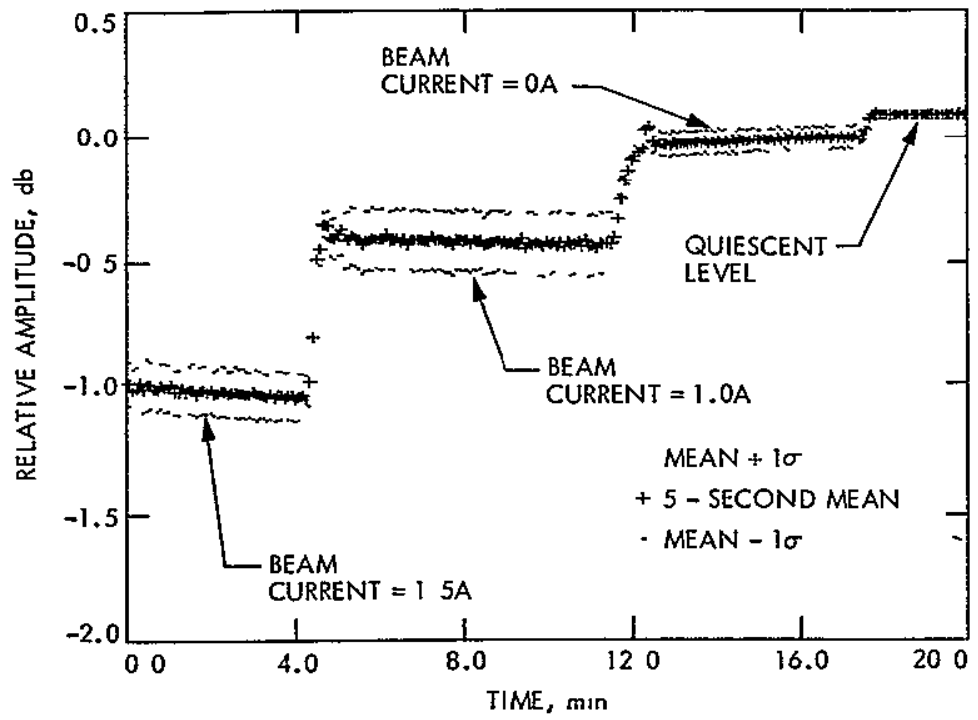

Fig. 15. Relative signal amplitude vs time, high power, E-horizontal polarization

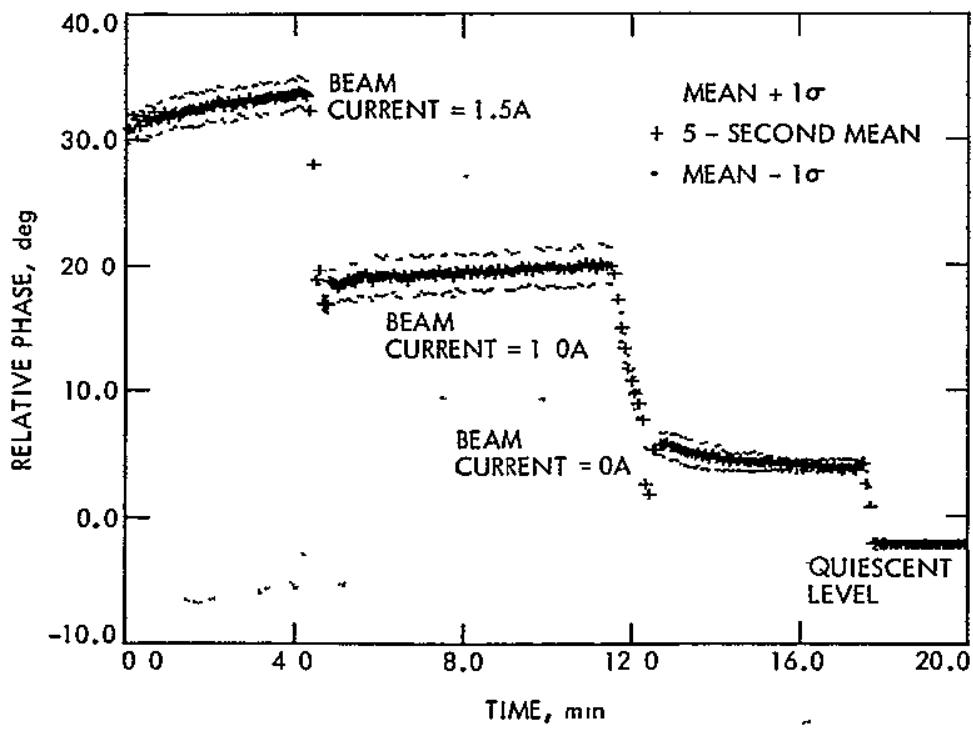

Fig. 16. Relative signal phase vs time, high power, E-horizontal polarization 


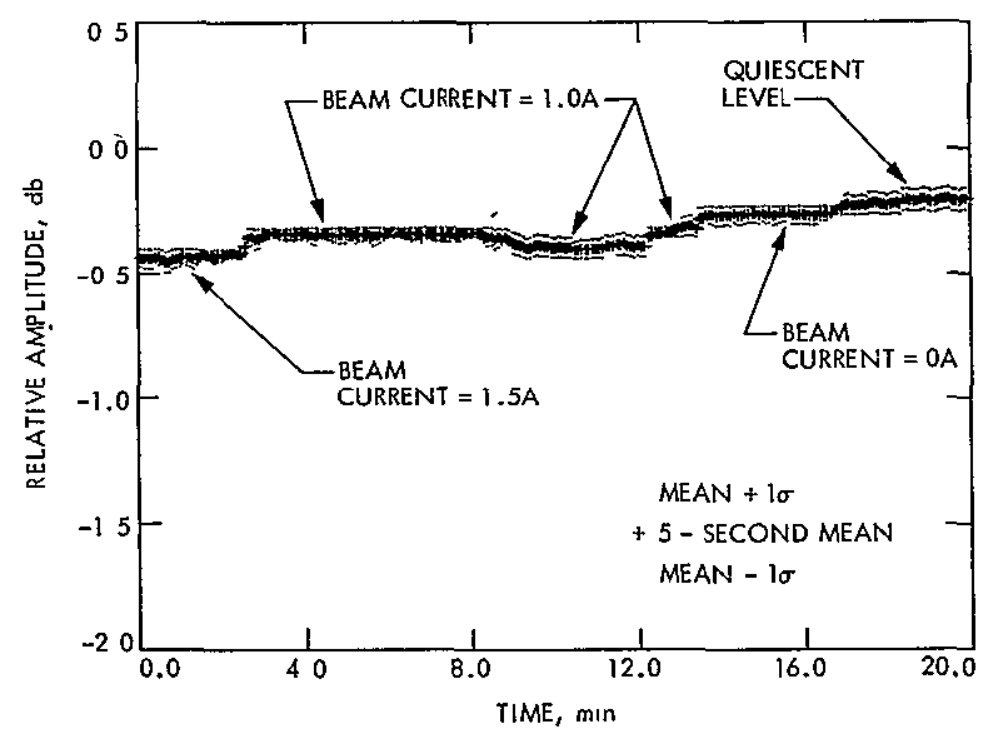

Fig. 17. Relative signal amplitude calıbration vs time, low power

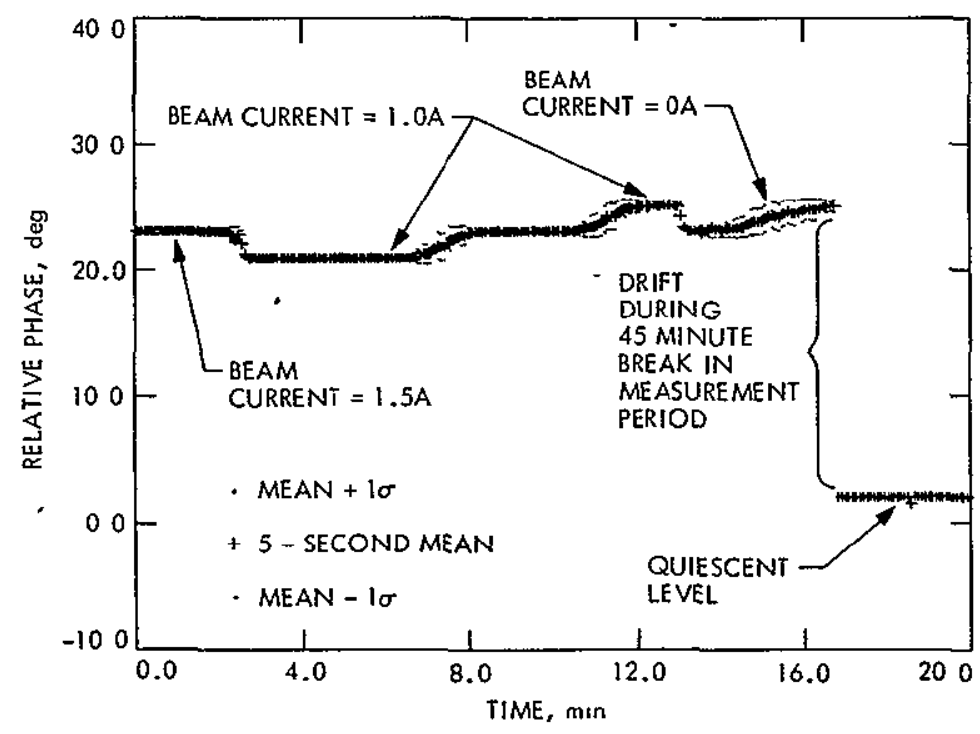

Fig. 18. Relative signal phase calibration vs time, low power. 


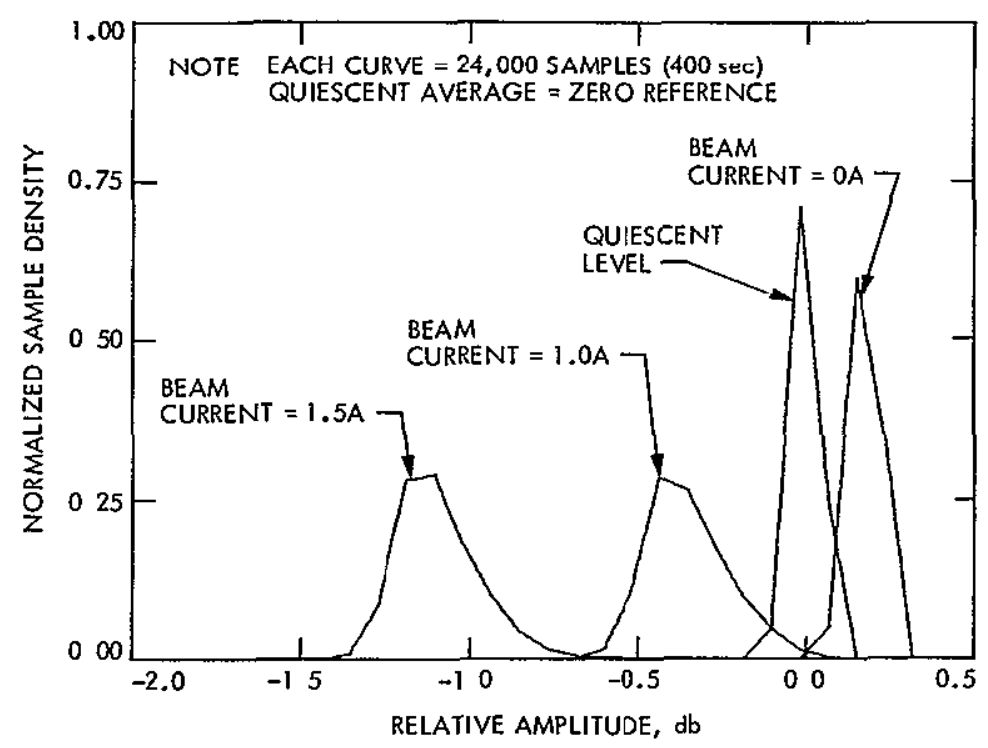

Fig. 19. Distributions of signal amplitude samples, low power, E-vertical polarization

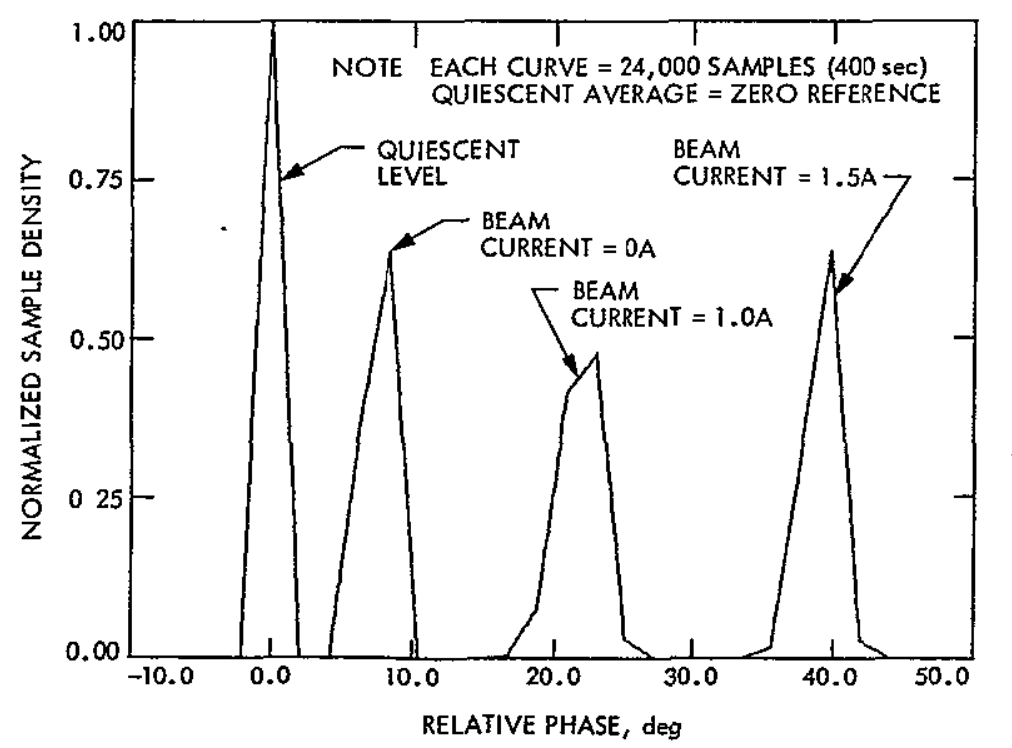

Fig. 20. Distributions of signal phase samples, low power, E-vertical polarization 


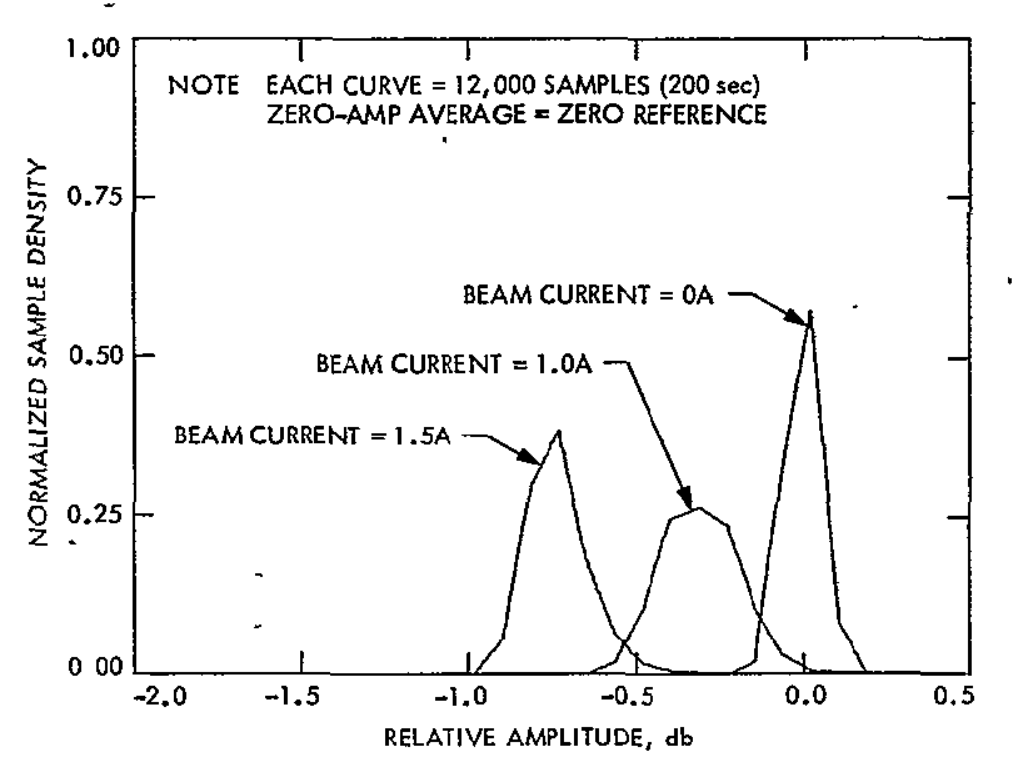

Fig. 21. Distributions of signal amplitude samples, low power, E-horizontal polarization

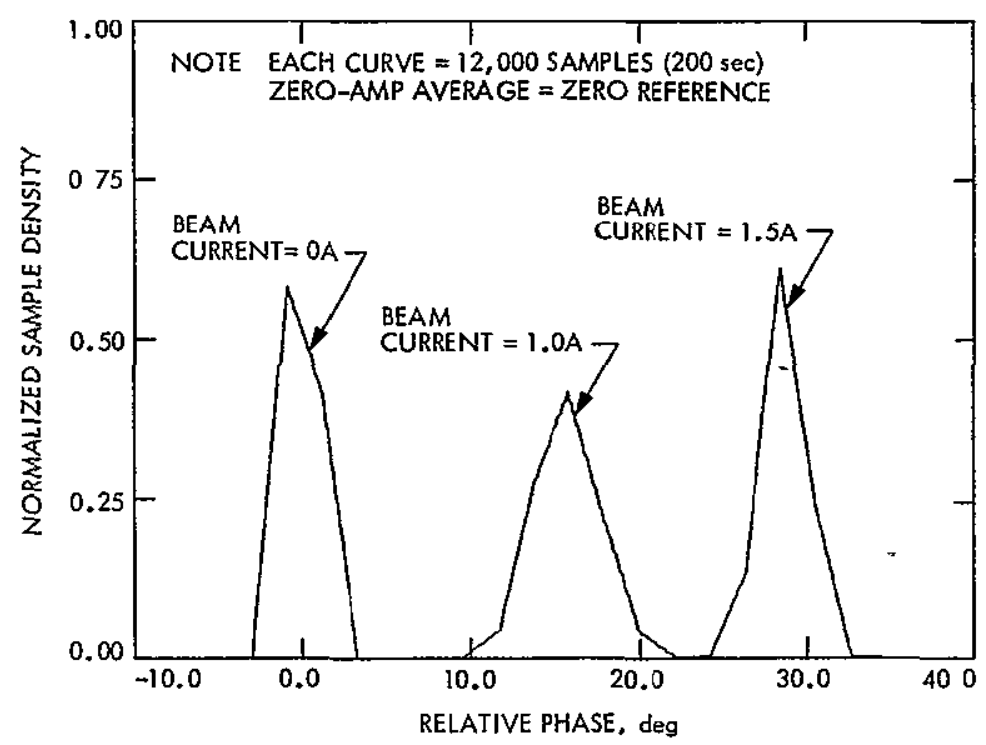

Fig. 22. Distributions of signal phase samples, low power, E-horizontal polarization 


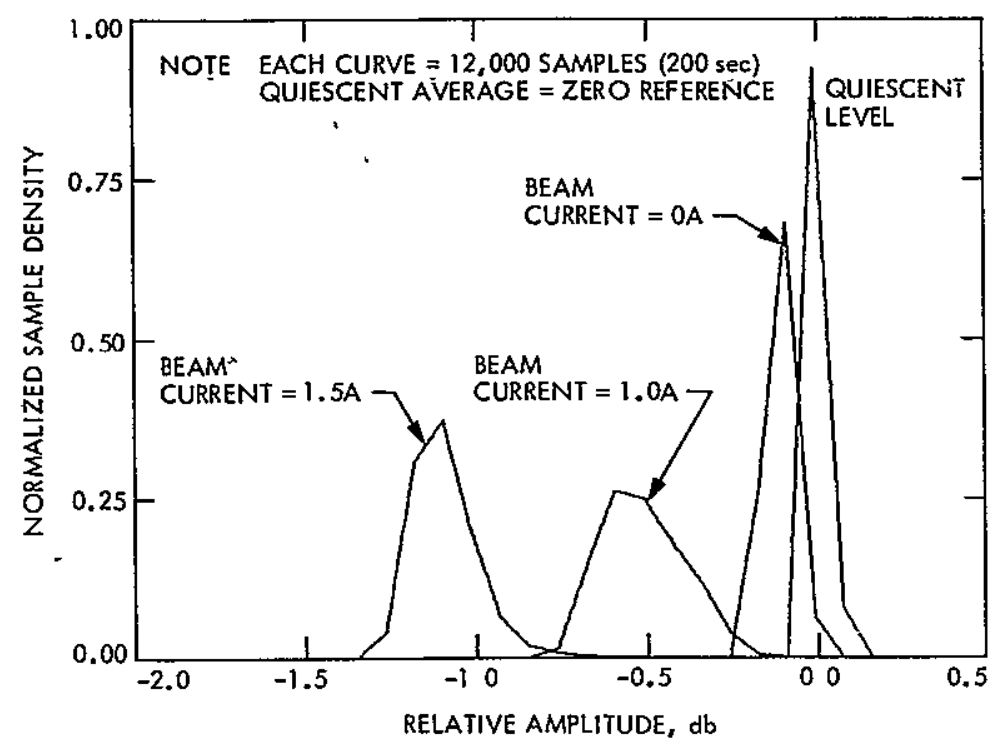

Fig. 23. Distrıbutions of signal amplitude samples, high power, E-horizontal polarization

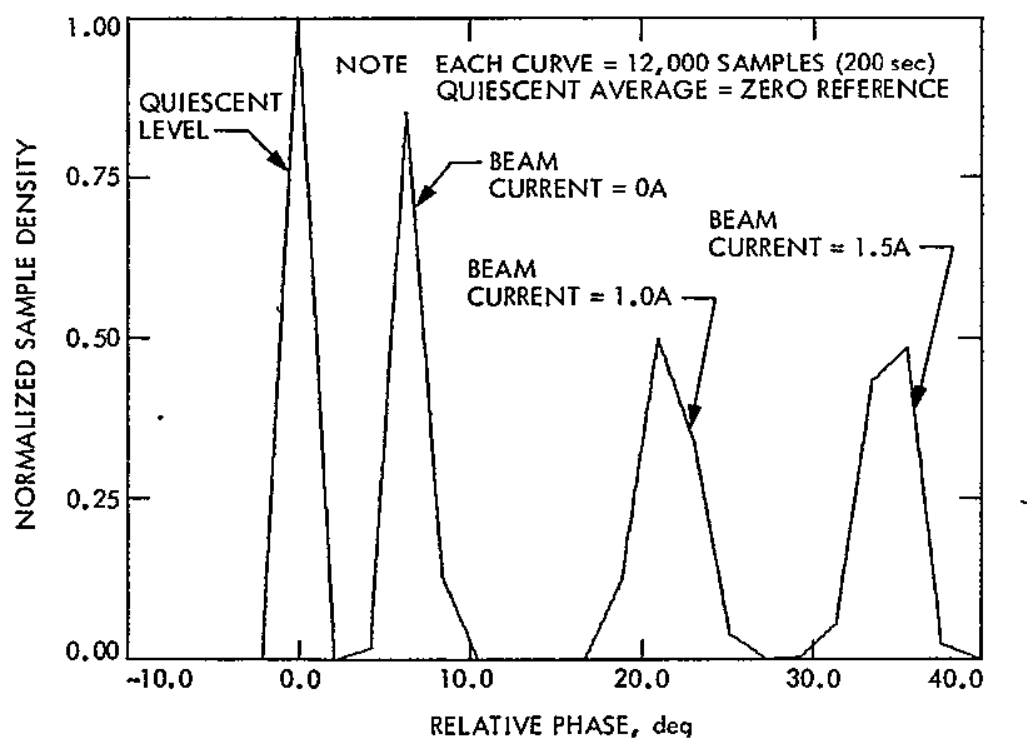

Fig. 24. Distributions of signal phase samples, high power, E-horizontal polarization 


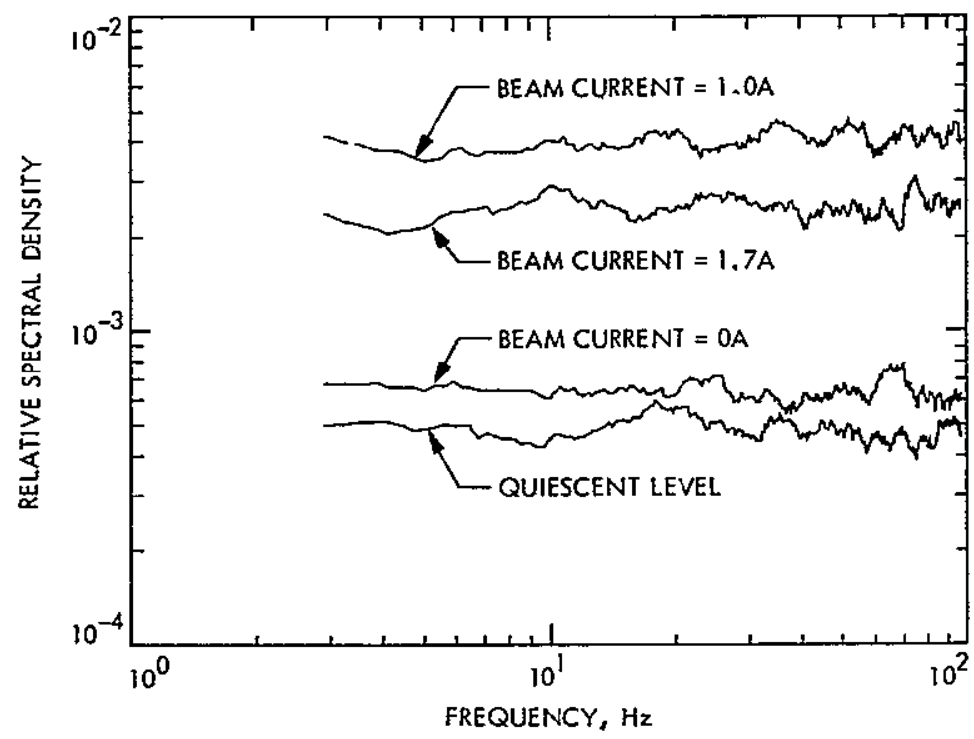

F1g. 25. Low-frequency spectra of signal amplitude, low power, E-vertical polarization

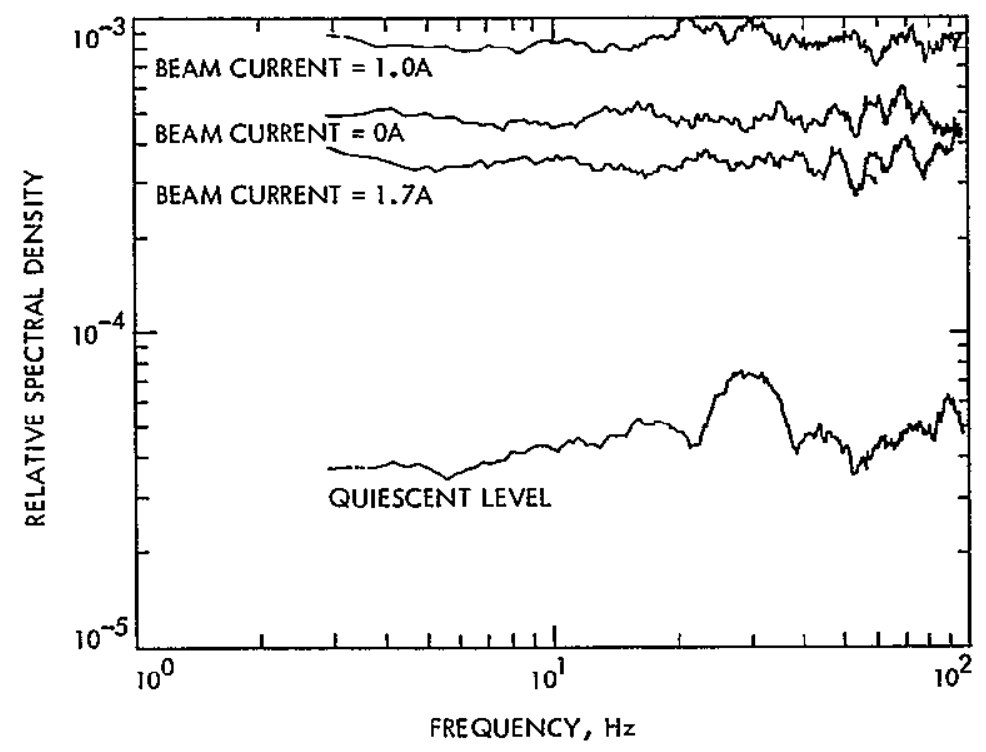

Fig. 26. Low-frequency spectra of signal phase, low power, E-vertical polarization 


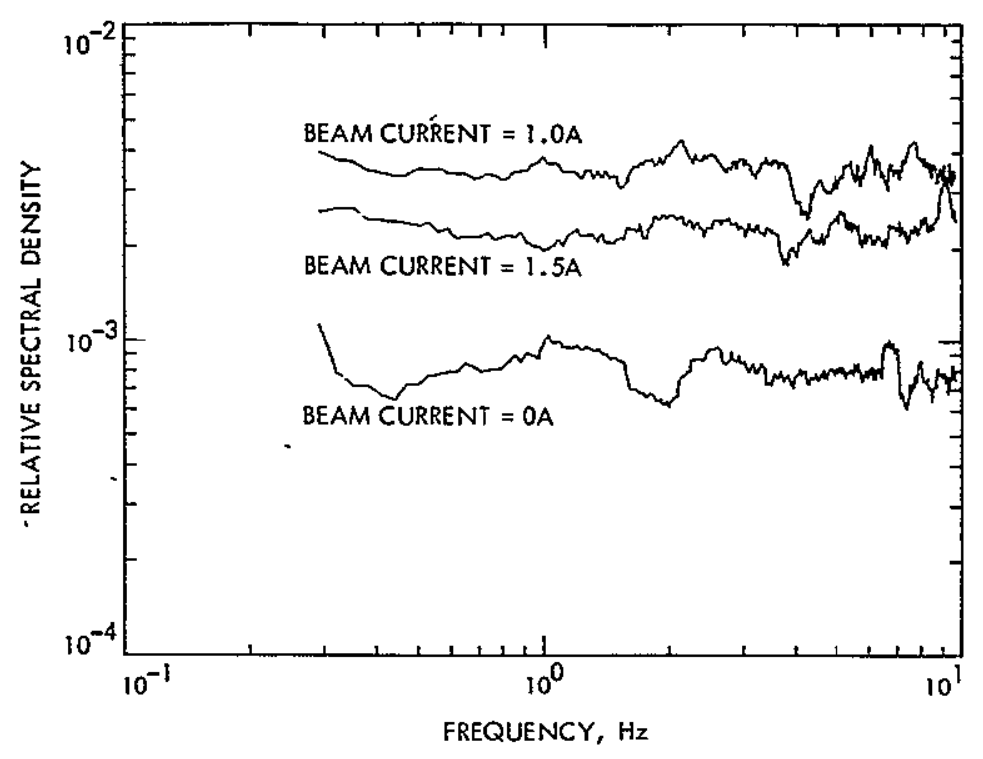

Fig. 27. Low-frequency spectra of signal amplitude, low power, E-horizontal polarization

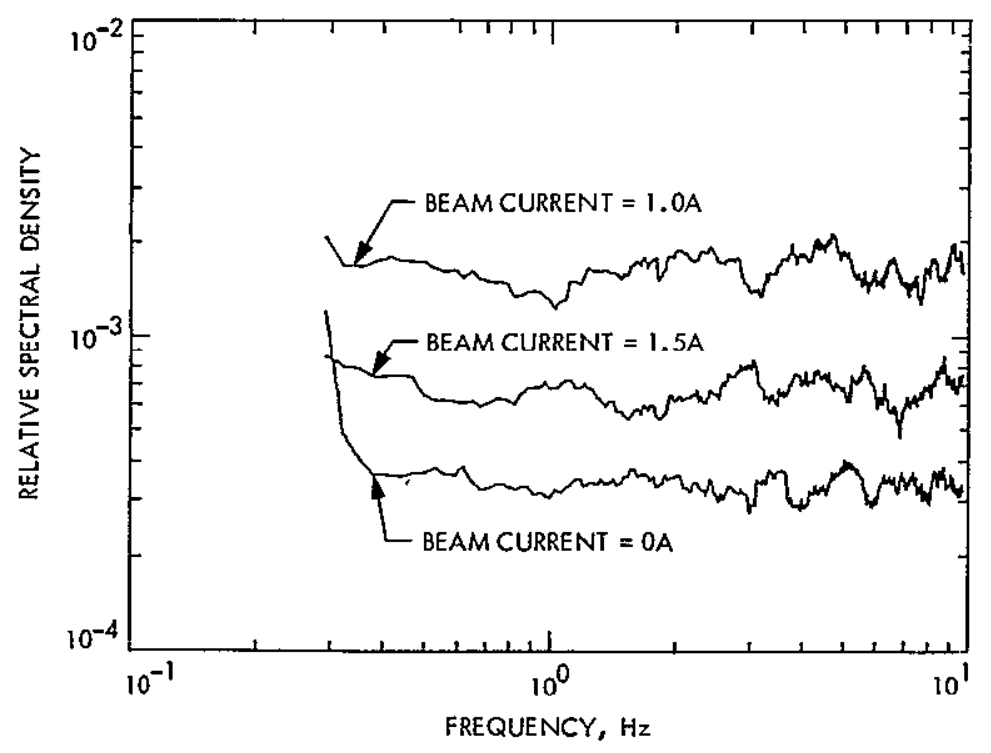

Fig. 28. Low-frequency spectra of signal phase, low power, E-horizontal polarization 


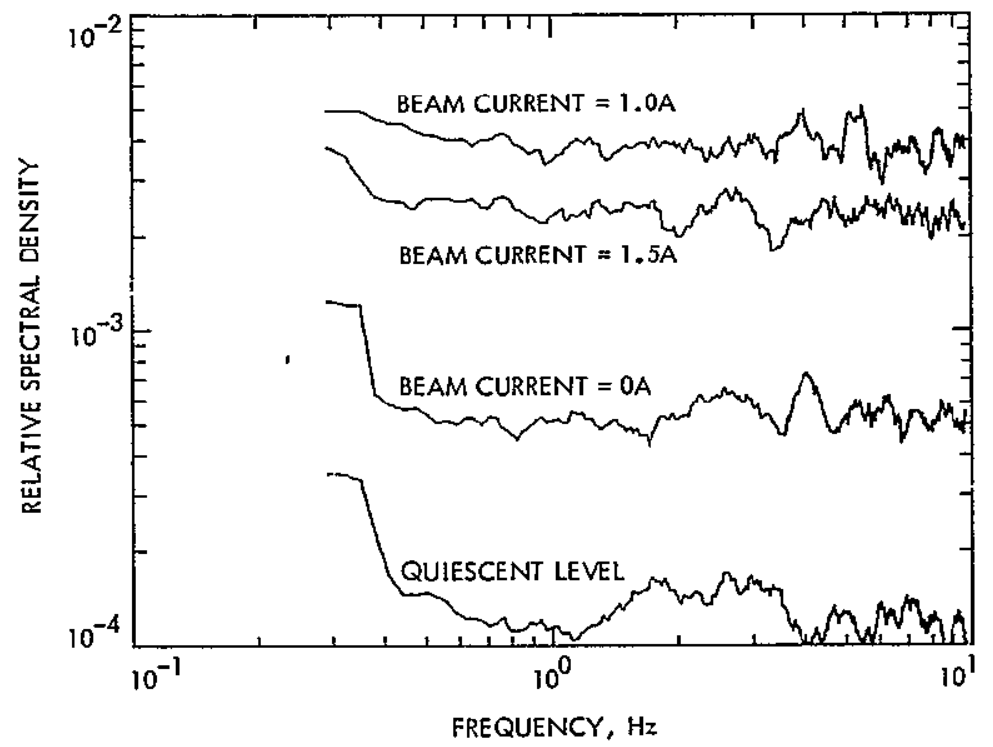

Fig. 29. Low-frequency spectra of signal amplitude, high power, E-horizontal polarization

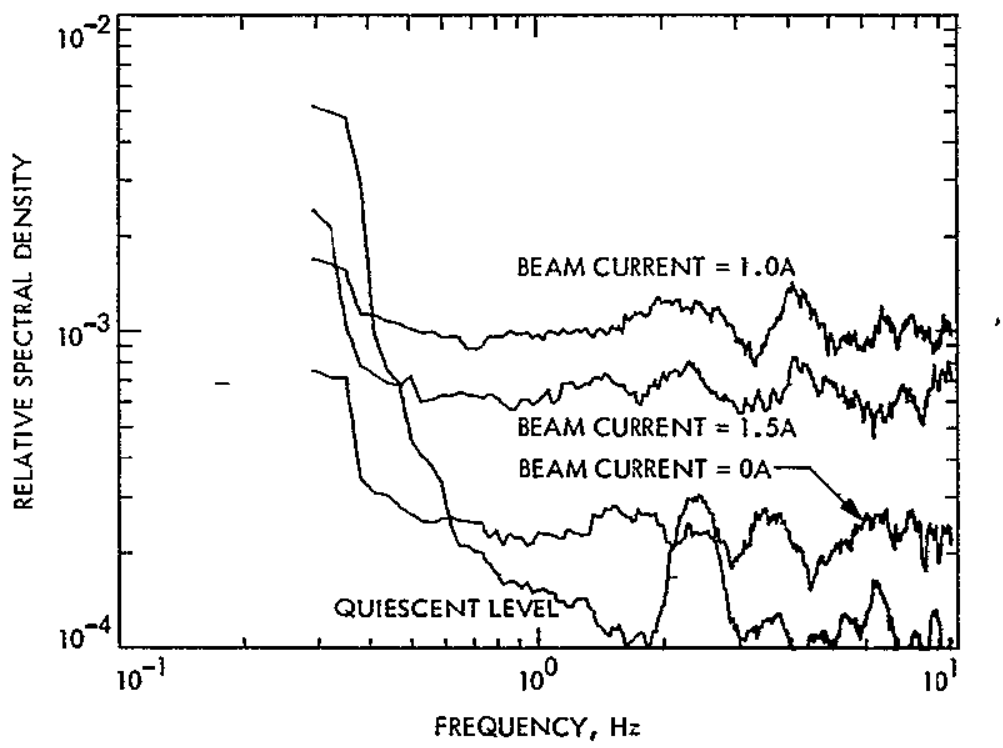

Fig. 30. Low-frequency spectra of signal phase, high power, E-hor tzontal polarization 


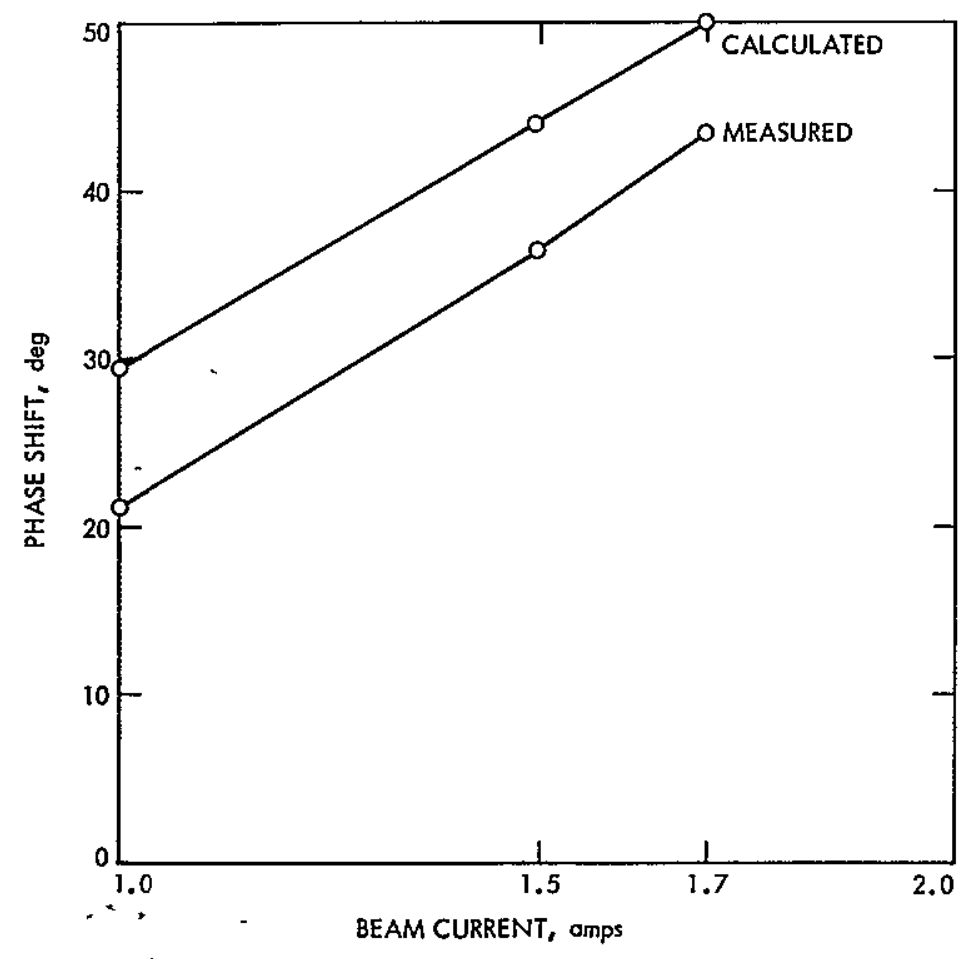

Fig. 31:" Signal phase shıft, measured and calculated 
APPENDIX A

CALCULATIONS

\section{ELECTRON PLASMA FREQUENCY CALCULATION}

The following electron plasma frequency, $\omega_{p_{e}}$, calculation is for the maximum electron density (from Figure 2) in the propagation path. The equation may be found in [7]:

$$
\omega_{p_{e}}=\left(\frac{n_{e} e^{2}}{\varepsilon_{0} m_{e}}\right)^{1 / 2}
$$

For the case of a one-ampere beam,

$$
\begin{aligned}
& n_{e} \cong 2.54 \times 10^{15} \text { electrons } / \mathrm{m}^{3} \\
& m_{e}=9.11 \times 10^{-31} \mathrm{~kg} \\
& e=1.602 \times 10^{-19} \mathrm{C} \\
& \varepsilon_{\mathrm{o}}=8.854 \times 10^{-12} \mathrm{~F} / \mathrm{m} \\
& \omega_{\mathrm{p}_{\mathrm{e}}} \cong\left(\frac{2.54 \times 10^{15}\left(1.602 \times 10^{-19}\right)^{2}}{8.854 \times 10^{-12}\left(9.11 \times 10^{-31}\right)}\right)^{1 / 2} \\
& \omega_{p_{e}} \cong 2.84 \times 10^{9} \mathrm{rad} / \mathrm{s}
\end{aligned}
$$




\section{ELECTRON GYROFREQUENCY (CYCLOTRON FREQUENCY)}

The equation used in the following gyrofrequency, $\omega_{b_{e}}$, is found in [10]. The flux density, $B_{0}$, used is given in [4]:

$$
\omega_{b_{e}}=\frac{e B_{o}}{m_{e}}
$$

For this case,

$$
\begin{aligned}
& \mathrm{B}_{\mathrm{o}} \cong 5 \times 10^{-5} \mathrm{~T} \\
& \omega_{\mathrm{b}_{\mathrm{e}}} \cong \frac{1.602 \times 10^{-19 \times\left(5 \times 10^{-5}\right)}}{9.11 \times 10^{-31}} \\
& \omega_{\mathrm{b}_{\mathrm{e}} \cong 8.8 \times 10^{6} \mathrm{rad} / \mathrm{s} \ll \omega_{\mathrm{r}_{f}} \cong 1.38 \times 10^{10} \mathrm{rad} / \mathrm{s}} \\
& \text { III. ION PLASMA FREQUENCY CALCULATION }
\end{aligned}
$$

\section{ION PLASMA FREQUENCY CALCULATION}

This plume was composed of an equal number of electrons and positively charged mercury ions. The following equation, from [10], will yield the approximate ion plasma frequency, $\omega_{p_{i}}$, for a highly singly-ionıed plasma:

$$
\omega_{p_{i}}=\left(\frac{n_{i} q_{i}^{2}}{\varepsilon_{0} m_{i}}\right)^{1 / 2}
$$

For the one-ampere beam current case,

$$
\begin{aligned}
& \mathrm{n}_{i} \cong 2.54 \times 10^{15} \text { ion } / \mathrm{m}^{-3} \\
& q_{i}=1.602 \times 10^{-19} \mathrm{C} \text { (singly charged ions) }
\end{aligned}
$$




$$
\begin{aligned}
& \varepsilon_{0}=8.854 \times 10^{-12} \mathrm{~F} / \mathrm{m} \\
& m_{i}=3.331 \times 10^{-25} \mathrm{~kg} \\
& \omega_{p_{i}} \cong\left(\frac{2.54 \times 10^{-15}\left(1.602 \times 10^{-19}\right)^{2}}{8.854 \times 10^{-12} \times 3.331 \times 10^{-25}}\right)^{1 / 2} \\
& \omega_{p_{i}} \cong 4.7 \times 10^{6} \mathrm{rad} / \mathrm{s} \ll \omega_{\mathrm{p}_{e}} \cong 2.84 \times 10^{9} \mathrm{rad} / \mathrm{s}
\end{aligned}
$$

IV. ION GYROFREQUENCY (CYCLOTRON FREQUENCY)

From [10],

$$
\omega_{b_{i}}=\frac{q_{i} B_{0}}{m_{i}}
$$

For this case,

$$
\begin{aligned}
& \mathrm{B}_{0} \cong 5 \times 10^{-5} \mathrm{~T}, q_{i}=1.602 \times 10^{-19} \mathrm{C}\left(\text { for } \mathrm{Hg}_{+}\right) \\
& \omega_{\mathrm{b}_{i}}= \frac{1.602 \times 10^{-19} \times\left(5 \times 10^{-5}\right)}{3.331 \times 10^{-25}} \\
& \omega_{\mathrm{b}_{i}}=24.0 \mathrm{rad} / \mathrm{s} \ll \omega_{\mathrm{r}_{f}} \cong 1.38 \times 10^{10} \mathrm{rad} / \mathrm{s}
\end{aligned}
$$




\section{ELECTRON-ION COLLISION FREQUENCY}

The RF wave absorption loss in the plume is related to its electron-ion collision frequency. The following electron-ion collision frequency calculation is based on equations given in [1i] (pg. 81):

If

$$
\begin{gathered}
i_{\mathrm{e}} \gg \mathrm{T}_{\mathrm{i}} \text { and } \mathrm{n}_{\mathrm{i}}=\mathrm{n}_{+}=\mathrm{n}_{\mathrm{e}} \\
\nu=\frac{5.5 \mathrm{n}_{\mathrm{e}}}{\mathrm{T}_{\mathrm{e}}^{3 / 2}}\left\{\ln \frac{280 \mathrm{~T}_{\mathrm{e}}}{\mathrm{n}_{\mathrm{e}}^{1 / 3}}+\frac{1}{3} \ln \frac{\mathrm{T}_{\mathrm{i}}}{\mathrm{T}_{\mathrm{e}}}\right.
\end{gathered}
$$

Under the conditions of this experiment, the electron-ion collision frequency is assumed to be the effective collision frequency of the plume. The calculation of this frequency follows:

$$
\begin{gathered}
T_{e} \cong 11,600^{\circ} \mathrm{K} \\
T_{i} \cong 650^{\circ} \mathrm{K} \\
n_{e} \cong 0.2 \times 10^{10} \text { electrons } / \mathrm{cm}^{3} \\
\nu \cong \frac{5.5\left(0.2 \times 10^{10}\right)}{(11,600)^{3 / 2}}\left\{\frac{280(11,600)}{\left(0.2 \times 10^{10}\right)^{1 / 3}+\frac{1}{3} \ln \frac{650}{11,600}}\right\} \\
\left.\nu \cong 6.1 \times 10^{4} \text { collisions/s }\right\}_{\mathrm{rf}} \cong 1.38 \times 10^{10} \mathrm{rad} / \mathrm{s}
\end{gathered}
$$

This effective collision frequency is much less than the RF carrier frequency resulting in a negligible absorption loss of the $\mathrm{RF}$ wave within the plume. 


\section{MAXIMUM POWER DENSITY}

An approximate maximum power density is calculated for the center of the plume along the propagation path. This power density, $P_{r}$, will be used to predict the linearity of the RF-plume interaction. The following calculations are based on [12]:

$$
\mathrm{P}_{\mathrm{r}}=\frac{\mathscr{D w}}{4 \pi \mathrm{r}^{2}}
$$

For the case under consideration

$$
\begin{gathered}
\mathscr{D}=\mathrm{G}_{\mathrm{o}} \text { (lossless antenna) } \cong 16 \mathrm{~dB} \text { or } 39.8 \\
\mathrm{w} \cong+23 \mathrm{dBm} \text { or } 0.2 \mathrm{~W} \\
\mathrm{r}=1.22 \mathrm{~m} \\
\mathrm{P}_{\mathrm{r}} \cong \frac{39.8(0.2)}{4 \pi(1.22)^{2}} \\
\mathrm{P}_{\mathrm{r}} \cong 0.43 \mathrm{~W} / \mathrm{m}^{2}
\end{gathered}
$$

\section{LINEARITY CONDITION}

The RF/Plasma interaction is a linear one at relatively low RF power density, $\mathrm{P}_{r}$, levels. The following linearity condition inequality was inferred from [7] (pg. 91):

$$
P_{r}=\frac{E^{2}}{2 \eta} \ll \frac{12 \pi^{2} m_{e}^{2} f^{2} k\left(T_{e}-T_{i}\right)}{m_{i} e^{2} \eta}
$$


For this case,

$$
\begin{aligned}
& m_{e}=9.11 \times 10^{-31} \mathrm{~kg} \\
& f=2.2 \times 10^{9} \mathrm{~Hz} \\
& \mathrm{k}=1.38 \times 10^{-23} \mathrm{~J} / \mathrm{K}^{\circ} \\
& \mathrm{T}_{\mathrm{e}} \cong 11,600^{\circ} \mathrm{K} \\
& \mathrm{T}_{\mathrm{i}} \cong 650^{\circ} \mathrm{K} \\
& m_{i}=3.331 \times 10^{-25} \mathrm{~kg} \\
& e=1.602 \times 10^{-19} \mathrm{C} \\
& \eta=377 \Omega \\
& \mathrm{P}_{\mathrm{r}} \ll \frac{12 \pi^{2}\left(9.11 \times 10^{-31}\right)^{2}\left(2.2 \times 10^{9}\right)^{2} 1.38 \times 10^{-23}\left(1.1 \times 10^{4}\right)}{3.331 \times 10^{-25}\left(1.602 \times 10^{-19}\right)^{2} 377} \\
& \mathrm{P}_{\mathrm{r}} \ll 22.4 \mathrm{~W} / \mathrm{m}^{2}
\end{aligned}
$$

The maximum RF power density at the center of the plume along the propagation path was on the order of one-half watt per s'quare meter. Therefore, the linearity condition holds for this experiment. 


\section{TYPICAL ELECTRON DENSITY CALCULATION}

Reference [5] describes the equations for calculating the electron density at any point in the plume and also provides the required parameter values for the RF propagation path used in this experiment. The electron density is the sum of the singly-charged ion density and twice the doubly-charged ion density:

$$
n_{e}=n_{+}+2 n_{++}
$$

where

$$
n_{+}=\left[\frac{J_{t}}{\bar{J}_{+}}\right] \frac{\left[1-\eta_{++}\right] \mathrm{I}_{T}}{\pi R_{0}^{2} \text { e } \bar{v}_{+}}
$$

and

$$
n_{t+}=\left[\frac{j_{+t}}{\bar{j}_{t+}}\right] \frac{\eta_{+t} I}{\pi R_{0}^{2} 2 \mathrm{e} \bar{v}_{t+}}
$$

The average ion velocities are

$$
\begin{aligned}
& \bar{v}_{+}=\sqrt{\frac{2 e v_{B}}{m_{i}}} \\
& \bar{v}_{++}=2 \sqrt{\frac{e V_{B}}{m_{i}}}=\sqrt{2} \bar{v}_{+} .
\end{aligned}
$$

At one-amp beam current, typical parameter values are

$$
\begin{aligned}
I & =1.0 \mathrm{amp} \\
\eta_{++} & =0.085
\end{aligned}
$$




$$
\begin{gathered}
R_{0}=0.1475 \mathrm{~m} \\
V_{B_{.}}=1,100 \text { volts } \\
{\left[\frac{j_{+}}{\overline{j_{+}}}\right]=0.75} \\
{\left[\frac{\dot{j}_{++}}{\left.\overline{\dot{j}_{++}}\right]=0.89}\right.}
\end{gathered}
$$

so

$$
\begin{aligned}
\bar{v}_{+} & =\left(2 \times 1.602 \times 10^{-19} \times 1.1 \times 10^{3} / 3.331 \times 10^{-25}\right)^{1 / 2} \\
& =32.53 \times 10^{3} \mathrm{~m} / \mathrm{sec} \\
n_{+} & =\frac{(0.75)(1-0.085)(1.0)}{\pi(0.1475)^{2}\left(1.602 \times 10^{-19}\right)\left(32.53 \times 10^{3}\right)} \\
& =1.93 \times 10^{15} \mathrm{~m}^{-3}
\end{aligned}
$$

and

$$
\mathrm{n}_{++}=7.51 \times 10^{13} \mathrm{~m}^{-3}
$$

Thus, the electron density is

$$
n_{e}=1.93 \times 10^{15}+2 \times 7.51 \times 10^{13}=2.08 \times 10^{15} \mathrm{~m}^{-3}
$$




\section{ADIABATIC APPROXIMATION CONDITION}

The phase shift and transmission models are substantially simplified if the reflection of $R F$ wave at the plasma boundaries is negligible. This condition exists when the following adiabatic approximation [7] (pg. 134) holds:

$$
\frac{1}{k} \frac{\mathrm{d} k}{\mathrm{dx}} \ll \frac{4 \pi}{\lambda}
$$

or approximately:

$$
\frac{1}{\kappa} \frac{\Delta x}{\Delta x} \ll \frac{4 \pi}{\lambda}
$$

The adiabatic approximation for the estimated worst case for this experiment is:

$$
\begin{array}{lll}
\kappa_{1}=0.968 & x_{1}=1.077 \mathrm{~m} & \lambda_{2.2 \mathrm{GHz}}=0.1364 \\
\kappa_{2}=0.963 & x_{2}=1.105 \mathrm{~m}
\end{array}
$$

let

$$
\begin{aligned}
k=\frac{k_{1}+k_{2}}{2} & =\frac{0.968+0.963}{2}=0.966 \\
\Delta x=k_{1}-k_{2} & =0.968-0.963=0.005 \\
\Delta x=x_{2}-x_{1} & =1.105-1.077=0.028 \\
\frac{1}{0.966} \frac{0.005}{0.028} \ll \frac{4 \pi}{0.1364} & \underline{\underline{0.185 \ll 92.129}}
\end{aligned}
$$

This shows the adiabatic approximation is valid in this case. 


\section{FAR FIEID CONDITION}

An approximate rule [7] (pg. 146) for the antenna far field is used in the following calculation:

$$
\mathscr{R} \geq \frac{\mathrm{A}^{2}}{\lambda}
$$

Let

$$
\begin{aligned}
A \cong 0.4 \mathrm{~m} \\
\lambda=0.1364 \mathrm{~m}(\text { at } 2.2 \mathrm{GHz}) \\
\mathscr{R} \gtrsim \frac{(0.4)^{2}}{0.1364} \\
\mathscr{R} \geqq 1.17 \mathrm{~m}
\end{aligned}
$$

In this experiment, the distance between the antenna windows and the center of the plume along the propagation path, $\mathscr{R}$, is equal to approximately 1.2 meters and thus meets the above condition.

\section{TYPICAL PHASE SHIFT CALCULATION}

The index of refraction for the plume, in this case, is less than that of freespace. The phase of the RF signal is advanced by the plasma relative to the plume off condition. The following equation was used to calculate the phase shift:

$$
\Delta \phi \cong \cdot \frac{\pi n_{e} \ell}{n_{c^{*}}} \quad \text { for } \quad \bar{n}_{e} \ll n_{c}
$$


For a one-ampere plasma condition,

$$
\begin{aligned}
& \bar{n}_{e} \cong 10^{15} \text { electrons } / \mathrm{m}^{3} \\
& \mathrm{n}_{c}=6.0 \times 10^{16} \text { electrons } / \mathrm{m}^{3}\left(\text { at } 2.2 \times 10^{9} \mathrm{~Hz}\right) \\
& \lambda=0.13627 \mathrm{~m} \\
& \ell=1.3373 \mathrm{~m} \\
& \Delta \phi \cong \frac{\pi\left(10^{15}\right) 1.3373}{0.13627\left(6 \times 10^{16}\right)} \\
& \Delta \phi \cong 0.514 \mathrm{rad}\left(\text { or } 29.4^{\circ}\right)
\end{aligned}
$$

The average electron density, $\bar{n}_{e}$, was arrived at by a graphical integration of the propagation path electron density curve [Figure 2] and the length of the propagation path within the plume, $\ell$, was chosen based on the significant area under this curve.

\section{TYPICAL TRANSMISSION CALCUIAATION}

The transmission coefficient $(T)$ is the ratio of the received power through the plume to the received power without the plume. The transmission effect, calculated here, is the result of spreading of the RF energy and not the result of RF energy absorption or reflection (see Figure 3 of the report for model geometry\}.

$$
T=\frac{D(L+2 \mathscr{R})}{4 m \mathscr{R}(L+\mathscr{R})+D(L+2 \mathscr{R})}
$$


where

$$
m=\frac{1}{\left(1-\frac{n_{e}}{n_{c}}\right)^{1 / 2}}-1
$$

Let

$$
\begin{aligned}
& \mathrm{D}=0.226 \mathrm{~m} \\
& \dot{L}=0.301 \mathrm{~m} \\
& \mathscr{R}=1.22 \mathrm{~m} \\
& \mathrm{n}_{e}=2.1 \times 10^{15} \text { electrons } / \mathrm{m}^{3}
\end{aligned}
$$$$
\mathrm{n}_{\mathrm{c}}(\text { at } 2.2 \mathrm{GHz})=6.0 \times 10^{16} \text { electrons } / \mathrm{m}^{3}
$$

then

$$
\begin{aligned}
& \mathrm{m}=\frac{1}{\left(1-\frac{2.1 \times 10^{15}}{6.0 \times 10^{16}}\right)^{1 / 2}-1} \\
& \mathrm{~m}=0.018
\end{aligned}
$$

and

$$
\begin{aligned}
& T=\frac{0.226(0.301+2 \cdot 1.22)}{4(0.018) 1.22(0.301+1.22)+0.226(0.301+2 \cdot 1.22)} \\
& T=0.822(\text { or }-0.85 \mathrm{~dB})
\end{aligned}
$$




\section{APPENDIX B}

\section{HORN ANTENNAS}

The test data on the two antennas used in the experiment is shown in Table B-l below. The data includes the antenna gain, .VSWR and antenna dimensions. A typical antenna is shown in Figure B-1.

Table B-1. Antenna test data

\begin{tabular}{|l|c|c|c|c|}
\hline \multirow{2}{*}{$f, \mathrm{GHz}$} & \multicolumn{2}{|c|}{ Antenna 1 } & \multicolumn{2}{c|}{ Antenna 2 } \\
\cline { 2 - 5 } & VSWR & Gain, dB & VSWR & Gain, dB \\
\hline 2.1 & 1.12 & 15.7 & 1.38 & 15.3 \\
\hline 2.2 & 1.12 & & 1.22 & \\
\hline 2.3 & 1.06 & 15.7 & 1.25 & 16.0 \\
\hline
\end{tabular}




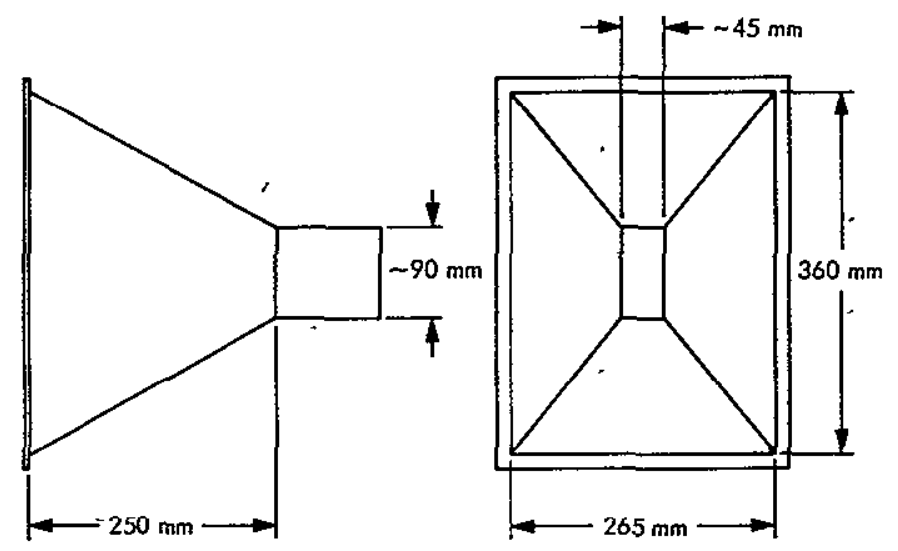

Fig. B-1. Transmit and recelve antennas 


\section{APPENDIX C}

\section{MICROWAVE ABSORBER VACUUM TESTS}

The use of foam-type microwave absorber is a logical solution to the problem of reducing RF reflections in a test chamber such as used here. The two absorber manufacturers, Emerson \& Cuming and Rantec, had little existing data on the reaction of their materials in a low-temperature vacuum environment. Thus, the study team initiated a series of tests to find a vacuumcompatible absorbing material.

Emerson \& Cuming and Rantec each supplied one piece of absorber $0.61 \mathrm{~m}$ by $0.61 \mathrm{~m}$ (about $2^{1} \times 2^{1}$ ) at a comparable cost. The $\mathrm{E} \& \mathrm{C}$ material was obtained from their standard process. The Emerson \& Cuming material specification is "absorber, CV-6." The Rantec material was obtained as a result of special processing which was specified by their process engtneers. The Rantec material specification is "absorber, EHP-5, white foam, impregnated, nonpainted."

Vacuum-compatibility is equivalent to low outgassing which is measured by the tank pumpdown pressure rate. The results of the pumpdown tests on the two test pieces are shown in Figure C-1. These test results show that the Rantec material had a much higher pumpdown rate than the $\mathrm{E} \& \mathrm{C}$ material. Examination of the test tank after the $E$ \& $C$ test revealed that the entire tank was covered with a silicone-like substance which was apparently the cause of the continuous outgassing. Thus, the Rantec microwave absorber was selected for use during this experiment.

After installing the absorber in the thruster test chamber, one incident of outgassing occurred the first time the thruster was turned on. Apparently the outer edge of the thruster plume was impinging on the inner edge of the absorber ring. This condition caused a very slight amount of absorber material outgassing which lasted only a few minutes and did no visible damage to the absorber. 


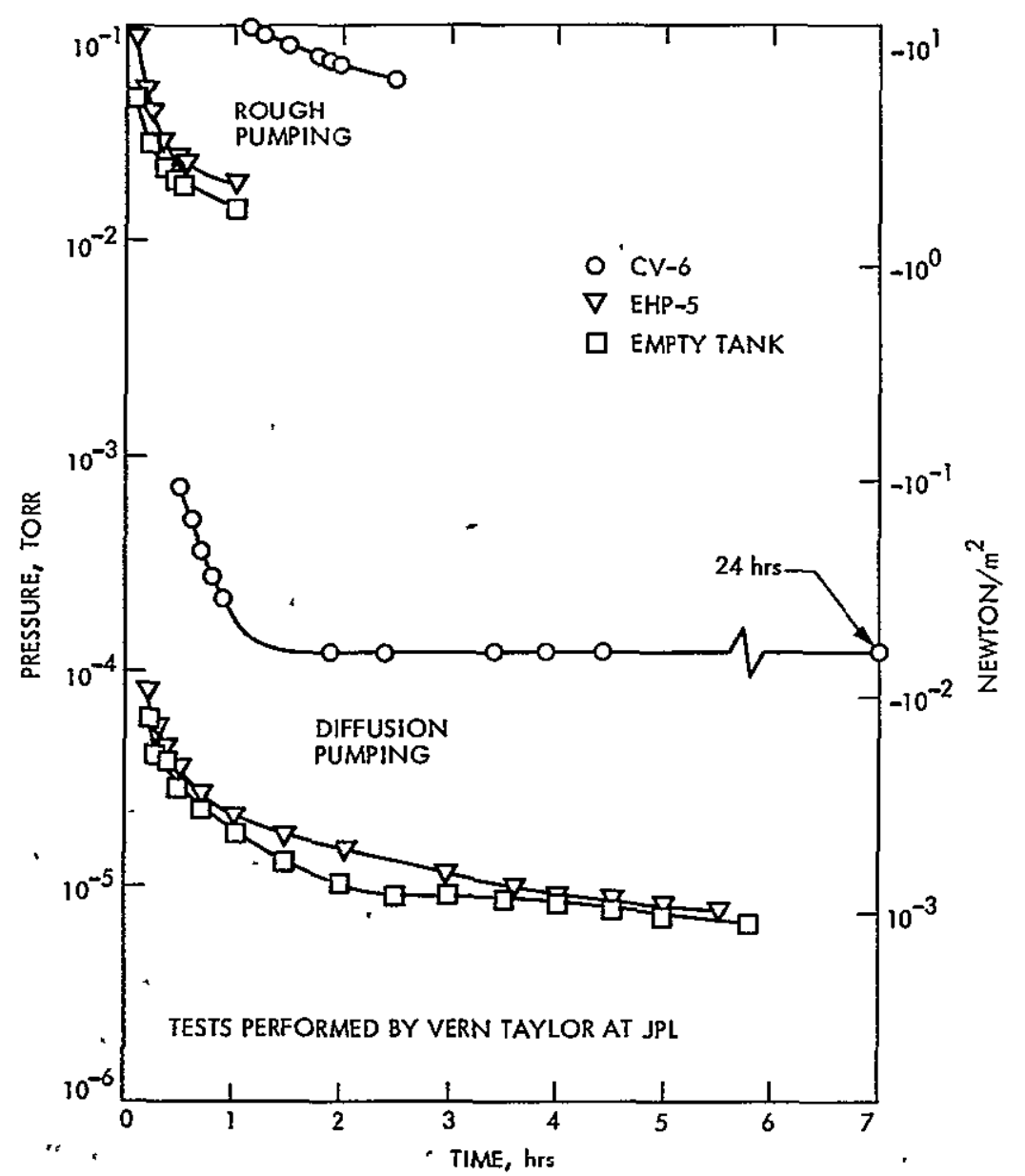

Fig. C-1. Absorber pumpdown test pressure profules 
APPENDIX D

EQUIPMENT LIST

NAME

a) NETWORK ANALYZER

b) HARMONIC FREQUENCY CONVERTER

c) PHASE-GAIN INDICATOR

d) SIGNAL GENERATOR

e) REFLECTION-TRANSMISSION UNIT

f) MICROWAVE AMPLIFIER (TWT)

g) SWEEP OSCILLATOR

h) STRIPCHART RECORDER

i) AMPLIFIER (4)

j) POWER METER

k) DISPLAY SECTION

1) SPECTRUM ANALYZER RF SECTION

m) SPECTRUM ANALYZER IF SECTION

n) STOR:AGE OSCILLOSCOPE

o) LOW PASS FILTER (2)

p) DIFFERENTIAL AMPLIFIER (2)

q) FREQUE्NCY COUNTER

r) FREQUENCY CONVERTER
MANUFACTURER TYPE

\begin{tabular}{|c|c|}
\hline $\mathrm{HP}$ & $8410 \mathrm{~A}$ \\
\hline HP & $8411 \mathrm{~A}$ \\
\hline $\mathrm{HP}$ & $8413 \mathrm{~A}$ \\
\hline $\mathrm{HP}$ & $8616 \mathrm{~A}$ \\
\hline $\mathrm{HP}$ & $8743 \mathrm{~A}$ \\
\hline $\mathrm{HP}$ & $491 \mathrm{C}$ \\
\hline $\mathrm{HP}$ & $692 B$ \\
\hline BRUSH & MARK II \\
\hline $\mathrm{HP}$ & $467 \mathrm{~A}$ \\
\hline HP & $435 \mathrm{~A}$ \\
\hline $\mathrm{HP}$ & $141 \mathrm{~T}$ \\
\hline $\mathrm{HP}$ & $8555 \mathrm{~A}$ \\
\hline $\mathrm{HP}$ & $8552 \mathrm{~B}$ \\
\hline TEKTRONIX & RM 564 \\
\hline $\mathrm{HP}$ & $5245 \mathrm{~L}$ \\
\hline $\mathrm{HP}$ & $5254 \mathrm{~B}$ \\
\hline
\end{tabular}


APPENDIX E

NORMAL THRUSTER OPERATING PARAMETERS

$\begin{array}{lc}\text { Arc voltage reference } & 37 \mathrm{~V} \\ \text { Arc current reference } & 5 \mathrm{~A} \\ \text { Beam current reference } & 1 \mathrm{~A} \\ \text { Delay time for main vaporizer } & 1 \mathrm{sec} \\ \text { Delay time for cathode vaporizer } & 1 \mathrm{sec} \\ \text { Cathode vaporizer heater gain } & 1 \mathrm{~A} / \mathrm{V} \\ \text { Main vaporizer heater gain } & 110 \mathrm{~A} / \mathrm{A} \\ \text { Magnetic baffle } & 40.5 \mathrm{ampere}-\mathrm{turns} \\ \text { Screen voltage } & 1100 \mathrm{~V} \\ \text { Accelerator voitage } & -500 \mathrm{~V}\end{array}$




\section{REFERENCES}

1. Poeschel, R. L., King, H.J., and Schnelker, D. E. , "An Engineering Model 30-cm Ion Thruster," AIAA paper No. 73-1084, AIAA 10th Electric Propulsion Conference, Lake Tahoe, Nevada, 10/31 - 11/2/73.

2. Fitzgerald, D.J., "Factors in the Design of Spacecraft Utilizing Multiple Electric Thrusters," AIAA Paper No. 75-404, AIAA 11 th Electric Propulsion Conference, New Orleans, La., March 19-21, 1975.

3. Kudo, I., Pless, L. C., and Pawlick, E. V., "Simulation of an IonThruster Control System, "to be published by the Jet Propulsion Laboratory, Pasadena, Calif.

4. Cowgill, R. M. , "SEP Thruster-Magnetic Mapping," Jet Propulsion Laboratory, Pasadéna, Calif., IOM 2946 - 74 - 50, March 20, 1974. (JPL internal document).

5 Cuffel, R. F., private communication, Jet Propulsion Laboratory, Pasadena, Calif., March 8, 1974.

6. Cuffel, R. F., "Thruster Plume Model," Jet Propulsion Laboratory, Pasadena, Calif., IOM 383-HT-4-348, March 28, 1974 (JPL internal document).

7. Heald, M. A. and Wharton, C. B., Plasma Diagnostics with Microwaves, J. Wiley and Sons, Inc., New York, 1965.

8. Springett, J.C. and Koller, F.J., "Results of the MVM'73 X-band Telemetry Experiment, "Jet Propulsion Laboratory, Pasadena, Calif., May, 1974 (JPL internal document).

9. Cohn, G.I., "Preliminary Examination of Problems in Communicating with an Ion-Rocket-Driven Interplanetary Spacecraft by Means of 2.1- to 2. 3-GHz Radio Signals, "Jet Propulsion Laboratory, Pasadena, Calif. , October, 1966 (JPL internal document).

10. Papas, C. H., Theory of Electromagnetic Wave Propagation, McGrawHill, New York, 1965.

11. Ginzburg, V. L., Propagation of Electromagnetic Waves in Plasma, Gordon \& Breach, New York, 1961.

12. Kraus, J. D., Antennas, McGraw-Hill, New York, 1950. 


\section{DEFINITION OF SYMBOLS}

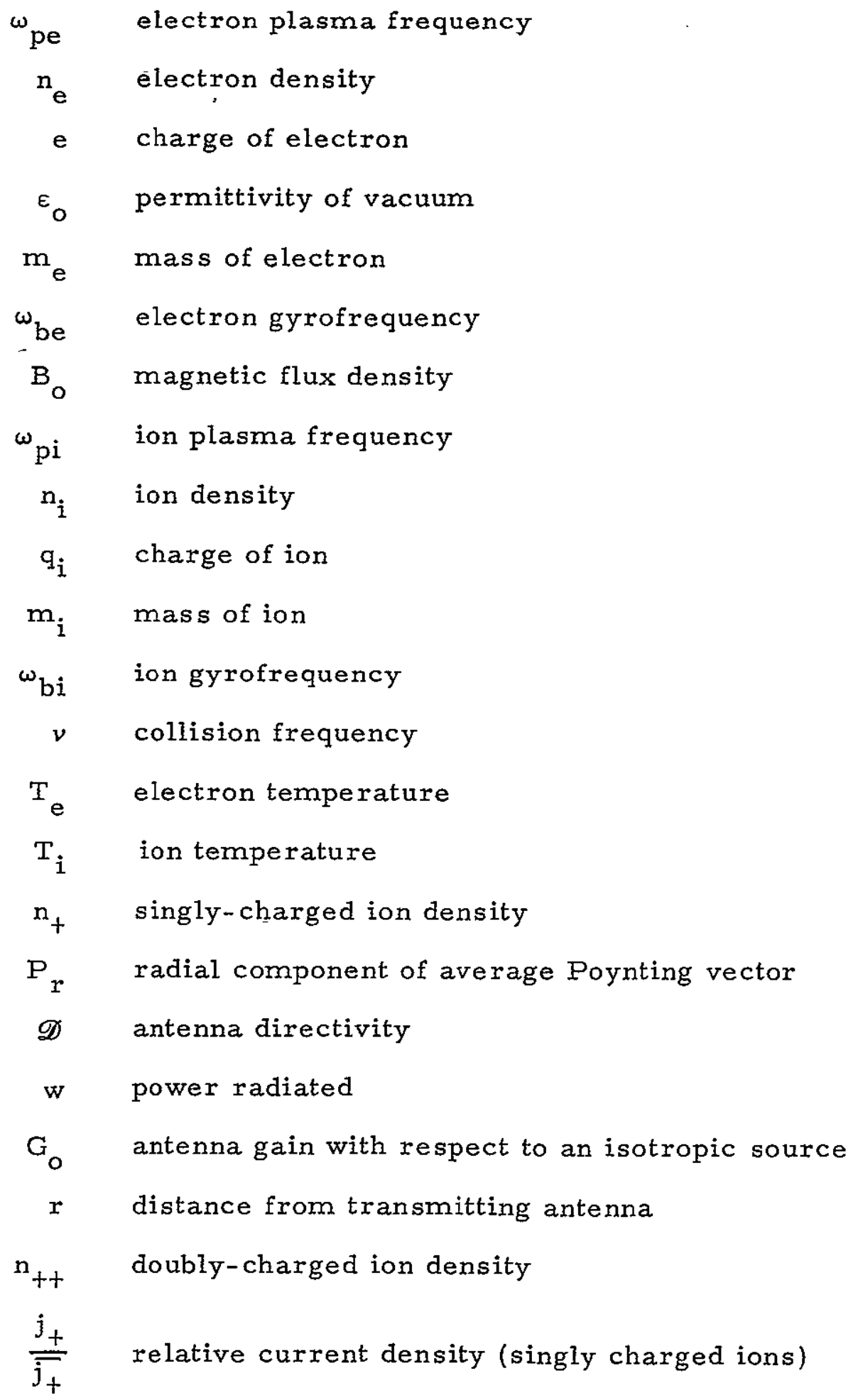




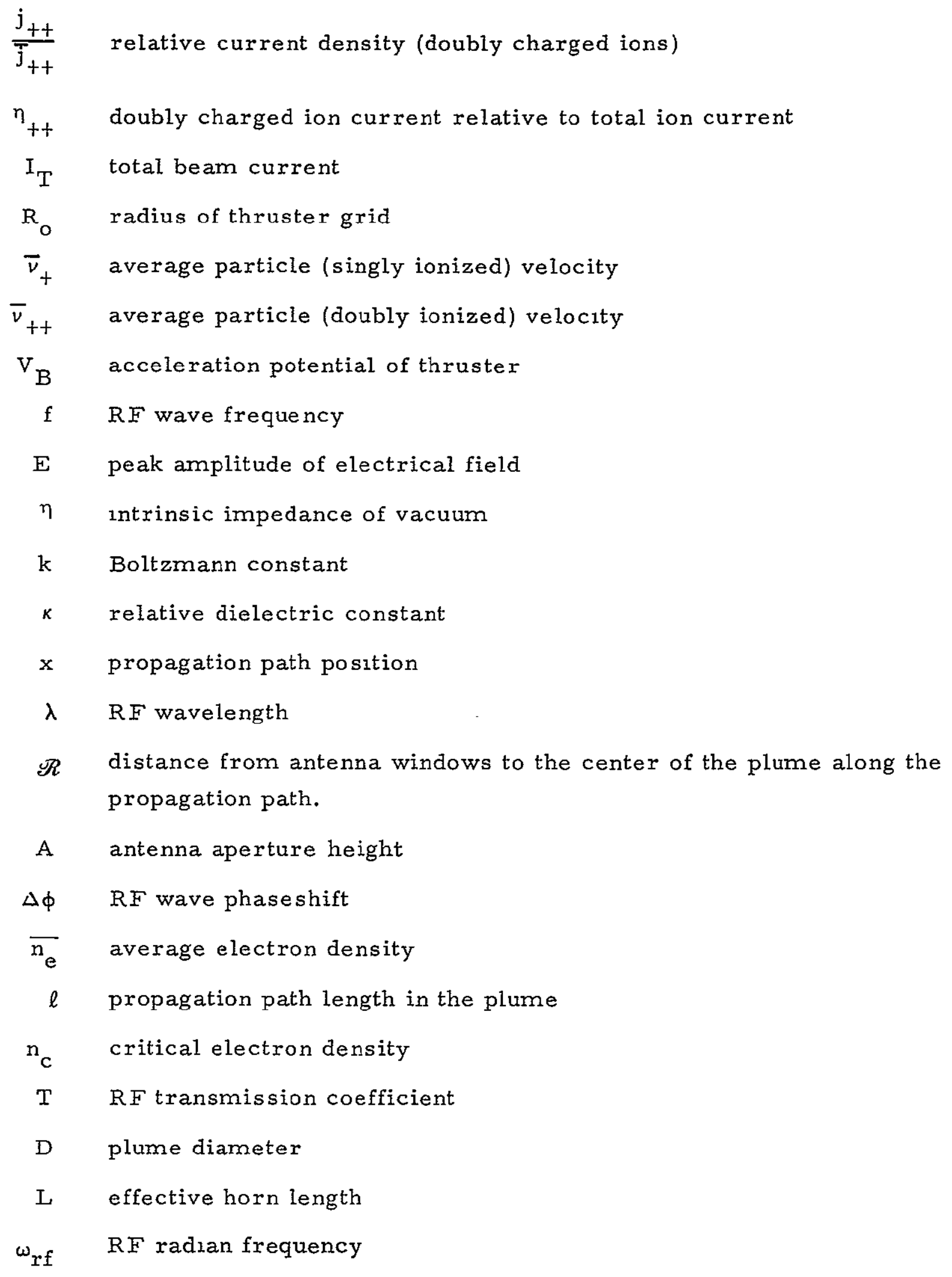

